\title{
Library Requirements of Masters of Art (Creative Writing) Students: Is the Class Library of The International Institute of Modern Letters meeting their Information Needs?
}

\section{by}

\begin{abstract}
Submitted to the School of Information Management,
Victoria University of Wellington

in partial fulfilment of the requirements for the degree of

Master of Library and Information Studies
\end{abstract}




\section{Acknowledgements}

I'd like to thank, firstly, my supervisor Rowena Cullen, for providing me with such an interesting research topic and for her support throughout my research. I'd also like to thank the staff of the International Institute of Modern Letters, Bill Manhire for agreeing to participate in an interview and the administrative staff, Clare and Katie, who answered my questions and helped me get my questionnaire off the ground. My gratitude also goes to Mary Innes, Collection Development Librarian at Victoria University of Wellington Central Library for also giving an interview. I am especially indebted to the 2005 students of the MA (Creative Writing) programme who responded to my questionnaire and who participated in my focus groups. Thanks also to those in my questionnaire pilot group who gave up their time and got confused. Edmund King, receives my heartfelt thanks (and one cheesecake) for his expert help on editing this final draft. Finally, I'd like to thank my partner Sean, for his amazing ability to cope with me in the craziness and stress, and who acted as my sounding board and editor - Arohanui. 
VICTORIA UNIVERSITY OF WELLINGTON

School of Information Management

Master of Library \& Information Studies

IMPORTANT DISCLAIMER

with respect to a MLIS Research Project (INFO 580)

\section{Library Requirements of Masters of Art (Creative Writing)}

Students: Is the Class Library of The International Institute of Modern Letters meeting their Information Needs?

\section{(hereafter referred to as 'The MLIS Research Project')}

being undertaken by

\section{Samantha April Callaghan}

in partial fulfilment of the requirements of the degree of Master of Library and Information Studies,

School of and Information Management, Victoria University of Wellington.

\section{Topic Commencement: $\quad 31$ October 2005}

1. Victoria University of Wellington and its Council, its members, staff, employees, students and agents undertake no duty of care in contract, tort, or otherwise, to users (whether direct or indirect) of the MLIS Research Project and make no warranties or representations of any kind whatsoever in relation to any of its contents.

2. The MLIS Research Project is only made available on the basis that all users of it, whether direct or indirect, must take appropriate legal or other expert advice in relation to their own circumstances and must rely solely on their own judgement and such legal or other expert advice.

3. Under no circumstances will Victoria University of Wellington and its Council, its members, staff, employees, students or agents be liable in any way whatsoever, whether in contract, tort (including negligence), for breach of any statutory or regulatory duty (to the fullest extent permissible by law), or otherwise, to any user (whether direct or indirect) of the MLIS Research Project for any loss or damage whatsoever arising directly or indirectly as a result of the use in any way of the MLIS Research Project.

4. Each exclusion in the clauses of this disclaimer and each protection given by it is to be construed as a separate exclusion applying and surviving even if for any reason any of the exclusions or protections are held inapplicable in any circumstance. 


\section{Contents}

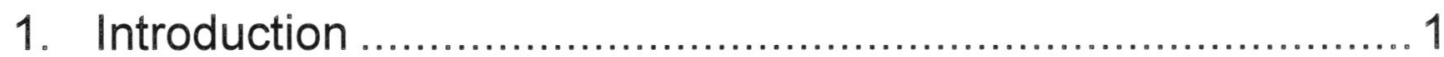

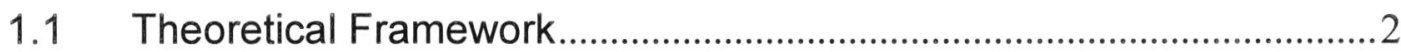

1.1.1 Kuhlthau's Information Search Process Theory ...............................2

1.1.2 Library Anxiety .................................................................................

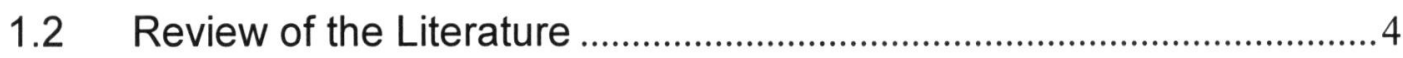

1.2.1 Theoretical Frameworks.............................................................

1.2.2 Identifying Student Information Needs..............................................

1.2.3 Library Usage and User Satisfaction................................................

1.2.4 The Importance of Reading to the Creative Writing Process .......8

1.2.5 Relationships Between Creative Writers, Libraries and Society .9

1.2.6 Knowledge Gap ........................................................................... 10

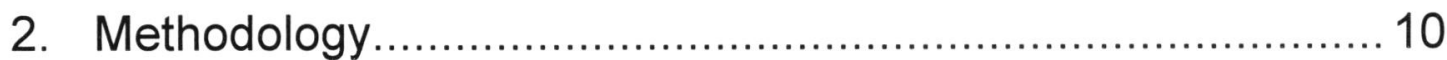

2.1 Operational Definitions ......................................................................... 12

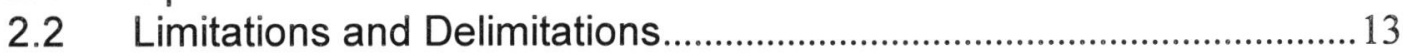

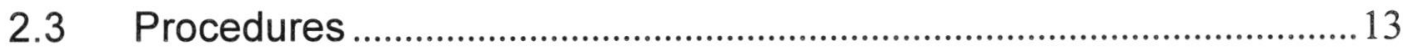

2.3.1 Populations and Samples ........................................................ 13

2.3.2 Research Instrumentation and Analysis ........................................ 14

2.3.3 Time Schedule ............................................................................ 16

2.3.4 Ethical Obligations ……………………....................................... 17

3. Data Analysis and Interpretation .................................... 17

3.1 Questionnaire................................................................................. 18

3.1.1 Reading, Libraries and the Creative Writing Process...................18

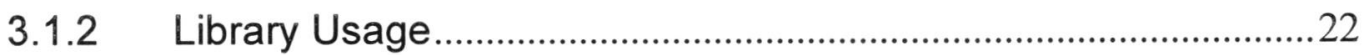

3.1.3 User Satisfaction ...........................................................................26

3.1.4 Libraries and Their Effect on How You Feel ..................................30

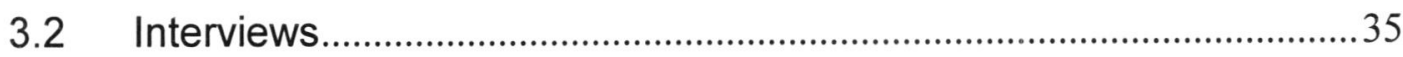

3.2.1 Student Focus Group Interviews ……………...............................36

3.2.1.1 The Importance of Creative Writing to Society ......................36

3.2.1.2 The Importance of Libraries to Creative Writing .....................38

3.2.1.3 Establishing Relationships between Creative Writers, Libraries and Society ..............................................................40

3.2.1.4 Quotes on Aspects of Creative Writing...................................45 
3.2.2 Interview with Bill Manhire, Director of the International Institute

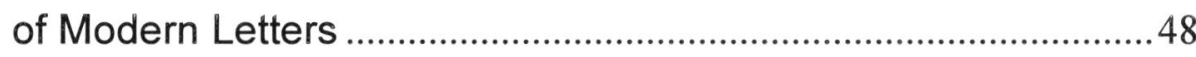

3.2.2.1 Perspectives as a Writer ....................................................... 48

3.2.2.2 Perspectives as a Teacher ....................................................50

3.2.3 Interview with Mary Innes, VUW Collection Development Librarian .52

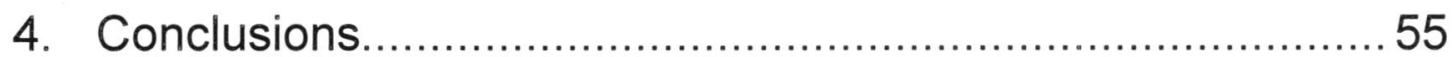

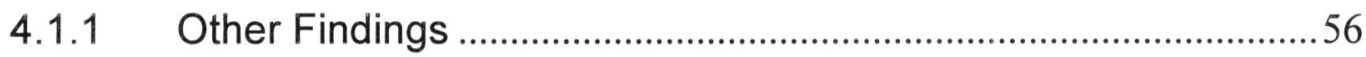

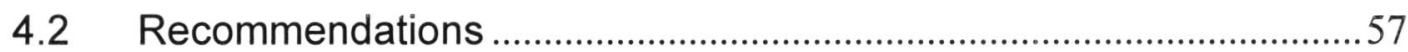

4.3 Study Limitations and Implications for Further Study .........................57

Appendix A - Project Gantt Chart................................... 62

Appendix B - Student Survey ....................................63 63

Appendix C - Student Interview Schedule.........................69

Appendix D - IIML Staff Interview Schedule........................ 71

Appendix E - VUW Librarian Interview Schedule .................. 72 


\begin{abstract}
To investigate whether the Class Library of the International Institute of Modern Letters was meeting the information needs of the students in the Master of Arts (Creative Writing) an exploratory research approach was used. A sequential mixed methodology study comprised of a questionnaire, with both quantitative and qualitative content, to canvass student responses as well as interviews with the Institute's students, its teaching staff, and the Collection Development Librarian of the Victoria University of Wellington Central Library. The findings showed that students made significant use of the Class Library, often in preference to the University Library. This usage was based on factors such as collection quality, proximity to the Institute, accessibility of the collection and the availability of reading material. Library anxiety experienced when using the Central Library is another probable factor. Based on these findings, it was recommended that the Institute retain the Class Library as an autonomous collection and not integrate it into the collection of the Victoria University of Wellington Central Library.
\end{abstract}

Keywords: Creative writing; Library Anxiety; Information needs; Class libraries; Faculty libraries. 


\section{Introduction}

Is the Class Library of The International Institute of Modern Letters meeting the information needs of its Master of Arts (Creative Writing) students? This is a significant question for The International Institute of Modern Letters as they decide whether to retain the Class Library as a separate entity over which they have control or to integrate it into the library collections of Victoria University of Wellington.

There has been little prior research in the discipline of library and information science into the information needs of Creative Writing students, so it was proposed to undertake a concurrent mixed methodology study to explore this research problem.

In the study, a questionnaire was used to identify the information needs of Creative Writing students; to investigate their usage of various libraries; and to explore the factors that influenced students' use of the libraries available to them.

Following the questionnaire (comprised of both quantitative and qualitative questions) three different 'populations' were interviewed. Creative Writing students were interviewed as members of focus groups, to investigate themes developed from the responses to the questionnaire and to contextualise the relationships that creative writers have with libraries and society. The Director of the Institute, Bill Manhire, was interviewed to determine the importance of reading in the creative writing process and the emphasis placed on libraries by teaching staff of the Master of Arts (Creative Writing) programme. Finally, an interview was conducted with Mary Innes, Collection Development Librarian at Victoria University of Wellington's Central Library, to consider how library staff identify and meet the information needs of Creative Writing students, and what relationships existed between the Central Library and the staff and students of The International Institute of Modern Letters.

Addressing this problem could also reveal how libraries and library staff might help those studying the creative arts. If such a relationship were discovered and further encouraged, it would follow that libraries might then make a semi-direct contribution to artistic expression and thus to the creative capital of the communities they are exist within. In providing resources as well as spaces where writers and other creative people may discover inspiration, libraries could be a factor contributing to their earning capability.

Libraries might then be seen as not only repositories for information but also as places of artistic creation. Emphasising this aspect of libraries might increase their profile in contemporary information discourse, which more frequently focuses on the Internet and the World Wide Web as providers of knowledge and stimulation.

Before examining the theoretical framework and literature that guided this study, it is important to establish the context in which the project itself takes place. Victoria University of Wellington offers the Master of Arts (Creative Writing) programme through The International Institute of Modern Letters as a limited-entry programme: the class of 2005 contained only thirty students.

The programme is offered as a one-year, full-time course and has two streams, Writing for the Page and Scriptwriting. Prospective students are required to include a 
writing sample with their enrolment applications. Assessment includes a final 'thesis' project, which is a submitted writing folio in the form of a play; a film or television script; a novel; a collection of short stories or poems; or a piece of creative nonfiction.

The class library is small by the standards of special libraries, and includes New Zealand-published fiction and non-fiction, as well as New Zealand-based creative writing serials. It also includes style manuals and other reference materials. Browsing is allowed, and circulation is controlled through a card-issue file. The collection is housed in a study-room in the Glenn Schaeffer building on the Kelburn campus of the University, which also includes a work-table, comfortable arm-chairs, and a computer networked with the University's student computer services.

Though the collection has existed for a number of years, little is known about its usage and it is this uncertainty that raises the question of whether the library is worth maintaining, or whether it would be better to integrate it into the central academic library.

\subsection{Theoretical Framework}

Two theories were used in approaching the research problem:

- Kuhlthau's Information Search Process theory, which models the information search processes that library users undertake when doing research; and

- Mellon's theory of Library Anxiety, which describes the anxiety that some tertiary students experience when using academic libraries.

\subsubsection{Kuhlthau's Information Search Process Theory}

Kuhlthau breaks the information search process down into six distinct stages:

1. Task Initiation, when a person first recognises that they have an information need;

2. Topic Selection, when a person identifies what their information need is;

3. Prefocus Exploration, when a person explores what they require to meet that information need;

4. Focus Formulation, when a person decides what they require to meet that information need;

5. Information Collection, when a person interacts with the library system and gathers information to meet their need;

6. and Search Closure, when a person has met their information need. ${ }^{1}$

Each stage is defined by the affective, cognitive, and physical realms common to each stage (see Table 1 below).

${ }^{1}$ Carol Collier Kuhlthau, "The Information Search Process", in Seeking Meaning: A Process Approach to Library and Information Services, (Norwood, N.J.: Ablex, 1993), 41-52. 
Figure 1. Model of the Information Search Process

\begin{tabular}{|c|c|c|c|c|c|c|}
\hline Stages & $\begin{array}{c}\text { Task } \\
\text { Initiation }\end{array}$ & $\begin{array}{c}\text { Topic } \\
\text { Selection }\end{array}$ & $\begin{array}{c}\text { Prefocus } \\
\text { Exploration }\end{array}$ & $\begin{array}{c}\text { Focus } \\
\text { Formulation }\end{array}$ & $\begin{array}{c}\text { Information } \\
\text { Collection }\end{array}$ & $\begin{array}{c}\text { Search } \\
\text { Closure }\end{array}$ \\
\hline Feelings & uncertainty & optimism & $\begin{array}{c}\text { confusion, } \\
\text { frustration, } \\
\text { and doubt } \\
\text { Thoughts }\end{array}$ & $\begin{array}{c}\text { clarity } \\
\text { ambiguity }\end{array}$ & $\begin{array}{l}\text { sense of } \\
\text { direction/confidence }\end{array}$ & relief \\
Actions & $\begin{array}{c}\text { seeking relevant } \\
\text { information }\end{array}$ & specificity \\
\hline
\end{tabular}

This theory deals specifically with how library users engage in the information search process, and is therefore pertinent in understanding why and how Creative Writing students use libraries to meet their information needs. It is also appropriate for use in this study because it takes into account the affective qualities ${ }^{2}$ resulting from the information search process and this ties in with the second theory of the framework, Library Anxiety.

\subsubsection{Library Anxiety}

The theory of library anxiety was developed from a grounded theory study with a sample of six thousand students conducted at a southern United States university, and was grounded in a qualitative methodology utilising student-written search journals. Library anxiety affected 75 to 85 percent of students in Mellon's ${ }^{3}$ seminal study, who "described their initial response to the library in terms of fear or anxiety.",

There were a number of aspects that contributed to library anxiety: perception of library size; an understanding of where to find the resources you need; and "...how to begin, and what to do."5

These aspects, and others, can be grouped into the following themes:

- Barriers with staff;

- Affective Barriers;

- Comfort with the Library;

- Knowledge of the Library; and

- Mechanical Barriers. ${ }^{6}$

The concept of library anxiety is explored in this study to better understand why Creative Writing students might use other libraries in preference to the academic libraries of Victoria University of Wellington.

\footnotetext{
- Based on a table in: Carol Collier Kuhlthau, "The Information Search Process", in Seeking Meaning: A Process Approach to Library and Information Services, (Norwood, N.J.: Ablex, 1993), 43.

${ }^{2}$ T. D. Wilson, "Models in Information Behaviour Research," Journal of Documentation 55, no.3 (1999):255-6.

${ }^{3}$ Constance A. Mellon, "Library Anxiety: A Grounded Theory and Its Development," College \& Research Libraries 47, no. 5 (1986): 160-5.

${ }^{4}$ Mellon, "Library Anxiety," 162.

${ }^{5}$ Mellon, "Library Anxiety," 162.

${ }^{6}$ Anthony J. Onwuegbuzie, Qun G. Giao, and Sharon Bostick, "Library Anxiety: Theory, Research, and Applications," in Research Methods in Library and Information Studies \#1, ed. R. R. Powell and L. Westbrook. Lanham, Maryland: The Scarecrow Press, Inc., 2004.
} 


\subsection{Review of the Literature}

There is a range of literature available to provide a basis upon which a project addressing whether the Class Library of the International Institute of Modern Letters is meeting the information needs of the Master of Arts (Creative Writing) students can be carried out. The literature supporting the two theories, the information search process and library anxiety, which contributed to the study's development are reviewed in Section 1.2.1. In addition, literature that pertained to the direct identification of student information needs (Section 1.2.2), library usage and user satisfaction (Section 1.2.3), the contribution of reading and libraries to the creative writing process (Section 1.2.4), as well as other relationships between libraries, creative writers and society are explored (Section 1.2.5).

\subsubsection{Theoretical Frameworks}

Many researchers have used Kuhlthau's theory of the information search process to provide them with a theoretical framework, particularly those working in the fields of library and information science. Eskola used the information search process theory, as well as others, in the development of a project looking at university students' information-seeking behaviour in a changing learning environment. ${ }^{7}$ Byström and Järvelin conducted a qualitative study (user-centric rather than system-based) to investigate task complexity and how this affected the information search process. ${ }^{8}$ This may have further implications for Creative Writing students, as they engage in different types of writing with differing degrees of complexity.

The theory of the information search process not only could provide an understanding of the process by which Creative Writing students find the material they need to fill an information need, but also a better understanding of what the problem is that students use libraries to solve.

The importance of the concept of library anxiety is clear when it is realised that the majority of tertiary students throughout their academic career will be required to use a library in some way to aid them in meeting assessment requirements, ${ }^{9}$ and, thus, are likely to suffer, at some point, a degree of library anxiety.

A number of researchers have further explored the theory and a significant body of literature has grown up around it. A selection of studies ${ }^{10,11}$ have looked at the relationship between library anxiety and trait anxiety (the phenomenon of anxiety

\footnotetext{
${ }^{7}$ Eeva-Liisa Eskola, “University Students' Information Seeking Behaviour in a Changing Learning Environment - How are Students' Information Needs, Seeking and Use Affected by New Teaching Methods?" Information Research 4, no. 2 (1998). http://informationr.net/ir/4-2/isic/eeskola.html [Accessed 11 May 2006]

${ }^{8}$ Katriina Byström and Kalervo Järvelin, "Task Complexity Affects Information Seeking and Use." http://www.info.uta.fi/tutkimus/fire/archive/KB20.pdf [Accessed 11 May 2006]

${ }_{9}^{9}$ Anthony J. Onwuegbuzie, Qun G. Jiao, and Sharon L. Bostick, "Library Anxiety: Theory, Research, and Applications," in Research Methods in Library and Information Studies \#1, ed. R. R. Powell and L. Westbrook (Lanham, Maryland: The Scarecrow Press Inc., 2004), 55.

${ }^{10}$ Qun G. Jiao, and Anthony J. Onwuegbuzie, "Prevalence and Reasons for University Library Usage," Library Review 46, no. 6 (1997): 411-20.

${ }^{11}$ Anthony J. Onwuegbuzie, and Qun G. Jiao, "Understanding Library-Anxious Graduate Students," Library Review 47, no. 4 (1998): 217-224.
} 
being experienced on an everyday basis), and library anxiety and learning style preference.

Findings from these demonstrate that: library anxiety is a unique phenomenon; learning style preference has an effect on the degree of library anxiety a graduate student may experience; and that library anxiety can affect how often students use a library. These studies were conducted using the Library Anxiety Scale that was first developed by Sharon Bostick in 1992, which has subsequently been modified by other researchers such as Van Kampen, ${ }^{12}$ who developed the Multidimensional Library Anxiety Scale "to assess six dimensions of an individual's perception of an academic library and the information search process."13

In each of these studies researchers have looked at samples of students drawn from a broad spectrum of disciplines, at either undergraduate or graduate level. This is based on the assumption that students have similar information needs, a concept that has not been examined in any great depth. There is a gap in the knowledge within this field as to how library anxiety might affect those who are creative writing students. It could be posited that library anxiety, experienced by those who use comparatively large academic libraries, is mitigated by the option of using other libraries that may provide a somewhat more relaxed space than those usually associated with academic libraries.

Antell ${ }^{14}$, who performed a phenomenological study to understand the issue of why college students use public libraries, provides some evidence that supports this case. Analysis of the seventeen in-depth interviews conducted by the researcher revealed that there were a number of reasons for students to use the public library in preference to their academic library. These were grouped into themes such as personal convenience, ease-of-use and familiarity with resources offered by the public library, the materials available, staff, and the subjective appeal of the library. Informal hypotheses developed prior to the study that were supported by the results included: the familiarity of using the public library prompted college students to use the public library in preference to college libraries; and users felt intimidated by the size of academic libraries to which they had access. All of these issues could be significant in developing an understanding of the library use patterns of creative writing students, in their class library and in the academic library.

\subsubsection{Identifying Student Information Needs}

There is little literature pertaining to creative writing tertiary students, at any particular level of study, that relates to their information needs. Indeed, there is little literature that explicitly documents the information needs of tertiary students, although the concept of information needs itself is well understood ${ }^{15}$. That the information needs of students act as a significant driver in the information seeking

\footnotetext{
${ }^{12}$ Doris J. Van Kampen, "Development and Validation of the Multidimensional Library Anxiety Scale," College \& Research Libraries 65, no. 1 (2004): 28-34.

${ }^{13}$ Van Kampen, Development and Validation of the Multidimensional Library Anxiety Scale, 28.

${ }^{14}$ K. Antell, "Why Do College Students Use Public Libraries? A Phenomenological Study," Reference \& User Services Quarterly 43, no. 3 (2004): 227-36.

${ }^{15}$ Carol Collier Kuhlthau, "The Information Search Process", in Seeking Meaning: A Process Approach to Library and Information Services, (Norwood, N.J.: Ablex, 1993), 33-53.
} 
process is equally well documented. Identifying information needs, however, is a difficult task as they are often dynamic in nature and develop over time.

Light ${ }^{16}$ conducted research using interviews with creative writing students from three different higher education providers in the United Kingdom to discover and describe what conceptions the students had of creative writing. He describes creative writing as "...a kind of writing that has often been conceptualised as qualitatively different from essay writing." 17 In his results there arose four types of conceptualisation that were defined by reader awareness, or how the student-writer perceived the effect of making their writing public and how it affected their writing. These were: releasing, where students expressed themselves with little regard for their audience; documenting, where the student writes for the reader but only at the level of their material; narrating, which integrates an understanding of writing, integrating material and the reader; and critiquing, which is concerned with writing with a well-developed understanding of the reader and readership forms. ${ }^{18}$ His findings did not support the idea that creative writing is fundamentally different from that of essay writing; instead, it highlighted that "...the student-writer as personal producer/consumer of meaning in terms of the other, as opposed to the student as public consumer/producer of meaning in terms of the self." 19 This implies that the information needs of creative writing students may not be significantly different from those of other tertiary students but without further research this cannot be confirmed.

The dearth of literature identifying student needs from the academic library perspective is not carried over into other types of libraries. Special libraries especially are required to be well aware of the information needs of their users to ensure that a high rate of user satisfaction is attained to justify funding from their parent organisation. Henczel ${ }^{20}$ reinforces this: "identifying and satisfying your clients' needs are critical to the viability of your service. ${ }^{, 21}$ She notes that information professionals often lack the empirical evidence to identify their users' information needs and thus are prone to assuming that they know what information is needed. In addition, she emphasises that not only must the information needs of clients be identified, but also what that information is needed for.

Identifying information users' needs may not necessarily be a difficult exercise. In two related studies, Cunningham ${ }^{22}$ and Bainbridge ${ }^{23}$, users themselves were able to, in natural language, articulate their information needs about visual arts and music to an

\footnotetext{
${ }^{16}$ Gregory Light, "From the Personal to the Public: Conceptions of Creative Writing in Higher Education," Higher Education 43 no. 2 (2002): 257-76.

${ }^{17}$ Light, From the Personal to the Public: Conceptions of Creative Writing in Higher Education, 259.

${ }^{18}$ Light, From the Personal to the Public: Conceptions of Creative Writing in Higher Education, 268272.

${ }^{19}$ Light, From the Personal to the Public: Conceptions of Creative Writing in Higher Education, 273.

${ }^{20}$ Sue Henczel, "To be Truly Accountable to Your Clients, Identify Their Needs," Information Outlook 9, no. 2 (2005): 32-3.

${ }^{21}$ Henczel, To be Truly Accountable to Your Clients, Identify Their Needs, 32.

${ }^{22}$ Sally Jo Cunningham, David Bainbridge, and Masood Masoodian, "How People Describe Their Image Information Needs: A Grounded Theory Analysis of Visual Art Queries," Paper presented at the Proceedings of the ACM/IEEE Joint Conference on Digital Libraries, Tucson, Arizona, 7-11 June 2004.

${ }^{23}$ David Bainbridge, Sally Jo Cunningham, and J. Stephen Downie, "How People Describe Their Music Information Needs: a Grounded Theory Analysis of Music Queries," Paper presented at ISMIR, John Hopkins University, Baltimore, Maryland, 26-30 October 2003.
} 
online reference system (Google Answers ${ }^{\mathrm{TM}}$ ). For visual-based queries, users identified any of a combination of: bibliographic information (artist, date, nationality, title, size, provenance, and publisher); contents (description of the form, objects or events depicted in the image); genre; where seen; colour; example (information seekers provided a representation of the work of interest); abstract information (concepts and themes touched on in the work); or affect ("terrifically moving," "terrifying"). ${ }^{24}$ Similar concepts were used by seekers of music information.

\subsubsection{Library Usage and User Satisfaction}

In determining whether a particular library or collection is meeting the information needs of its users, usage of resources and user satisfaction with the library are often evaluated. Again, there is no literature addressing faculty libraries for creative writing programmes. There is, however, a study that provides an understanding of usage of resources by the Fine Arts faculty at Texas Tech University (TTU). ${ }^{25}$ This research looked at the usage of information resources in both the academic libraries of TTU as well as personal libraries, which "Fine Arts faculty have traditionally built...to supplement the various formats necessary for instruction, research, and creative activities." 26 The authors found that "the majority of respondents indicated that they preferred to build their own collections as well as use TTU Libraries. ${ }^{, 27}$ Reed and Tanner also asked which information sources faculty directed students to for research purposes. They found that faculty almost always referred students to the main campus libraries and sometimes to the faculty libraries. This may have had a significant impact on usage levels of the faculty libraries by students but this was not covered by the research.

In contrast, the majority of literature that examines usage and user satisfaction addresses either academic libraries that service a range of faculties, or public libraries. For example, Simmonds and Andaleeb ${ }^{28}$ addressed this issue within the context of three academic libraries in Erie, Pennsylvania. They surveyed 188 students over the course of three semesters to evaluate what factors influenced students to use the libraries. These factors included service quality, collection make-up, and user demographics. In addition, they raised the issue of identification of user needs and the incorporation of those needs into the strategic planning of academic libraries. The authors were unclear, however, as to whether this would lead to higher usage of library resources.

Jiao and Onwuegbuzie ${ }^{29}$ have also looked at the prevalence of and reasons for university library usage, but their study was conducted over a diverse sample of

\footnotetext{
${ }^{24}$ Cunningham, How People Describe Their Image Information Needs: A Grounded Theory Analysis of Visual Art Queries, 48.

${ }^{25}$ Bonnie Reed and Donald R. Tanner, "Information Needs and Library Services for the Fine Arts Faculty," Journal of Academic Librarianship 27, no. 3 (2001): 229-33.

${ }^{26}$ Reed, Information Needs and Library Services for the Fine Arts Faculty, 232.

${ }^{27}$ Reed, Information Needs and Library Services for the Fine Arts Faculty, 231.

${ }^{28}$ Patience L Simmonds and Syed Saad Andaleeb, "Usage of Academic Libraries: the Role of Service Quality, Resources, and User Characteristics," Library Trends 49, no. 4 (2001): 626-34.

${ }^{29}$ Qun G Jiao and Anthony J. Onwuegbuzie, "Prevalence and Reasons for University Library Usage," Library Review 46, no. 6 (1997): 411-20.
} 
students and thus is of little use when addressing usage in the class library context which displays little diversity in a disciplinary context.

In addition to usage, there is determination of user satisfaction to further clarify the information needs of users. Ascertaining user satisfaction is often based on user satisfaction surveys. The motivation in undertaking such surveys, however, is not based solely on determining how well a library is fulfilling the information needs of its users, but also on demonstrating the value of the services and resources provided to the parent organisation. ${ }^{30,31}$ There is a substantial body of scholarly literature in this area that elaborates on the process of developing a user satisfaction survey instrument and the theory that underpins it. ${ }^{32,33}$

An example drawn from the literature, Cullen, ${ }^{34}$ emphasises the provision of quality service by which high user satisfaction can be determined and reported to reinforce the importance of retaining a library in an increasingly competitive information market. She has determined this by reviewing a number of published user surveys, predominantly from academic libraries.

The concept of user satisfaction and its importance is not only realised in libraries; it has been well understood and elaborated within the field of business studies and, more specifically, that of marketing. Alexander ${ }^{35}$ states that "Finding out what customers need and constantly striving to achieve customer satisfaction is crucial.",36

It must be noted, however, that usage statistics do not wholly reflect the usefulness of items issued to or browsed by users, and that user satisfaction is perhaps not necessarily dependent on whether their information need has been met or not.

\subsubsection{The Importance of Reading to the Creative Writing Process}

An implicit approach to identify students' information needs would involve elucidating what contribution reading (and, through reading, libraries) might make to the creative writing process. There is some research in this area: creative writers themselves have repeatedly pointed to the importance of reading in their creative writing practices. ${ }^{37,38}$ Mempo Giardinelli, for example, has said that "I am...certain that my role as a writer derives from my education as a reader,... [a] book education that, above all, stimulated freedom and limitless curiosity." ${ }^{39}$ Silas House emphasises

\footnotetext{
${ }^{30}$ Joseph R. Matthews, "Determining and Communicating the Value of the Special Library," Information Outlook 7, no. 3 (2003): 26-31.

${ }^{31}$ Lynette Miller, "User Satisfaction Surveys," Australasian Public Libraries and Information Services 17, no. 3 (2004): 125-33.

${ }^{32}$ Miller, User satisfaction surveys, 125-33.

${ }^{33}$ Xi Shi, "A Theory-guided Approach to Library Services Assessment," College \& Research Libraries 66, no. 3 (2005): 266-77.

${ }^{34}$ Rowena Cullen, "Perspectives on User Satisfaction Surveys," Library Trends 49, no. 4 (2001): 66286.

${ }^{35}$ Keith Alexander, "Identifying and Managing Facilities Needs," Facilities 11, no. 3 (1993): 18-21.

${ }^{36}$ Alexander, Identifying and Managing Facilities Needs, 20.

${ }^{37}$ Ron Chepesiuk, "Writers at Work: How Libraries Shape the Muse," American Libraries 25, no. 11 (1994): 984-7.

${ }^{38}$ E. Ethelbert Miller, "A Writer's View: "Journey to a Sacred Place"," American Libraries 31, no. 6 (2000): 67-8.

${ }^{39}$ Mempo Giardinelli, "The Library in the Life of a Writer," IFLA Journal 30, no. 4 (2004): 288-92.
} 
the importance of reading in the creative writing process: "the only way to be a good writer is to read great books..." ${ }^{40}$ Creative writers have also talked about their use of libraries as writing spaces and for research. ${ }^{41}$

Those who teach creative writing agree that reading is an important aspect of the creative writing process. Freiman states that: “... the writer function of reading, which is part of the process of the social construction of the text, the 'activity of the mind in knowing' is exposed and articulated by creative writing processes. ${ }^{, 42} \mathrm{He}$ felt that creative writing students who are actively engaged in reading will connect with a text in a significantly different way to a "...reader who is only a reader." "training" creative writing students require to be active, rather than passive, readers is a concept that requires further study.

Foster ${ }^{44}$ attempted to determine the degree to which reading affected the creative writings of college students in his 'Personal Essay' class. This was a test of "the uses of readings in the writing classroom... [being]... usually justified on two principles their modelling effect and stimulative impact." ${ }^{, 45}$ In his study he discovered that, in terms of style or content, very little of the creative output of the class was modelled on the supplied readings. They did, however, stimulate an enriched awareness of the techniques and tones that published writers use. ${ }^{46}$ This study only addressed one particular type of creative writing, essays, and so the lack of direct impact of reading on their creative output may not hold true for those engaged in producing other types of creative writing work.

\subsubsection{Relationships Between Creative Writers, Libraries and Society}

In addition to the reading-writing relationships discussed above, libraries may contribute to the creative writing process through the establishment of a variety of library-writer relationships. There is no doubt that libraries and writers have a range of relationship modes. Libraries can, for example, be incubators for and supporters of local writing talent, as when the North Carolina State University Libraries introduced their "Author of the Year" programme to "...foster the careers of promising, young local writers." ${ }^{, 47}$ Writers, conversely, can be promoters and supporters of libraries, as was the case when the State Library of Victoria (Australia) was under threat due to

\footnotetext{
${ }^{40}$ Susan Eubank, "Silas House: What the Library Did for Me," Kentucky Libraries 65, no. 3 (2001): 35.

${ }^{41}$ Chepesiuk, Writers at Work: How Libraries Shape the Muse, 984-7.

42 Marcelle Freiman, "Crossing the Boundaries of the Discipline: A Post-Colonial Approach to

Teaching Creative Writing in the University," Text 5 no. 2 (2001).

http://www.gu.edu.au/text/school/art/text/oct01/freiman.htm [Accessed 8 August 2005]

${ }^{43}$ Freiman, Crossing the Boundaries of the Discipline: A Post-Colonial Approach to Teaching Creative Writing in the University.

${ }^{44}$ David Foster, "Reading(s) in the Writing Classroom," College Composition and Communication 48, no. 4 (1997): 518-39.

${ }^{45}$ Foster, Reading(s) in the Writing Classroom, 518.

${ }^{46}$ Foster, Reading(s) in the Writing Classroom, 537.

${ }^{47}$ Jinnie Y. Davis, "Writers and Libraries: a Symbiotic Partnership - Author Programs at North Carolina State University," North Carolina Libraries 57, no. 2 (1999): 57-61.
} 
government cutbacks. ${ }^{48}$ Libraries can also support creative writing at the community level by providing meeting spaces for writing groups to use, and by organising creative writing workshops and other events. ${ }^{49}$ But is there a direct contribution to the creative writing process when a library opens its collections up for the use of creative writers?

Finally, Freiman touches on the importance that creative writing can have to society: "it can be argued that creative writing is political; it recasts prevailing social, historical and political structures. As such it is potentially disruptive, as is the most powerful literature both inside and outside the canon at any given time. $" 50$ This is a topic that has generated much opinion, but little research has been done to clarify how important creative writing is to society and culture.

\subsubsection{Knowledge Gap}

It was evident that there was very little literature that pertained to class libraries that support post-graduate creative writing programmes. The majority of literature that addressed the issues identified above were drawn from the LIS discipline and covered the range of library types, academic to public to special. Other literature came from the fields of education and business.

The knowledge gap revealed by the lack of existing literature clearly needed to be addressed. The proposed study was intended to question the students and academic staff of the Master of Creative Writing programme at Victoria University of Wellington, to determine what the students' information needs were and how well the class library met those information needs. In addition, the importance of reading to writing, and the relationships between creative writers, libraries, and society were to be investigated. The study would also attempt to determine whether library anxiety was a factor affecting usage of the class library and the main campus academic library.

Though the scope of the proposed project was, of necessity, narrow due to limitations of timeframe and population, it had the potential to make a significant contribution to a little-understood and under-studied area of library science. Even though the relationship between reading and writing had been explored in an educational context, the direct contribution of libraries, as providers of reading resources and reading space, to the creative process had not been sufficiently explored.

\section{Methodology}

To determine whether The International Institute of Modern Letters should be retained or integrated, there needed to be developed a more in-depth understanding of whether the Class Library was meeting the information needs of the Master of Arts (Creative Writing) students. As there was no previous literature that addressed the

\footnotetext{
${ }^{48}$ Cameron Barrie, "A Mouthpiece of Writers: The Contribution of Australian Libraries," The Australian Library Journal 48, no. 3 (1999): 263-9.

${ }^{49}$ Philippa Reed, "Writing Activities in Libraries," Assistant Librarian 88, no. 2 (1995): 28-30.

${ }^{50}$ Freiman, Crossing the Boundaries of the Discipline: A Post-Colonial Approach to Teaching Creative Writing in the University.
} 
problem directly, a set of study objectives were developed to ensure that the research question was answered. These included:

- To identify the information needs of Creative Writing students;

- To identify what problems create the information needs of Creative Writing students;

- To determine how Creative Writing students used material they found in libraries;

- To determine usage of the International Institute of Modern Letters Class Library;

- To determine the Master of Arts (Creative Writing) students overall library usage;

- To identify any factors that influence the usage of the International Institute of Modern Letters Class Library in preference to other available library resources;

- And finally, to determine whether the established usage of the International Institute of Modern Letters Class Library and the associated factors that underline this usage justify the retention of the library.

From these, a number of specific research questions were developed to ensure that the objectives could be translated into measurable outcomes from the research results.

- What are the information needs of the students?

- What problems cause Creative Writing students to experience information needs?

- How do Creative Writing students use the material they find in libraries in the creative writing process?

- What drives them to use the libraries accessible to them?

- Do the Master of Arts (Creative Writing) students make use of the IIML Class Library?

- Do the students make use of the VUW Central Library?

- Do the creative writing students use one library in preference of another? If so, why?

- And lastly, should the IIML Class library be retained as an independent collection, or integrated into the VUW Library network?

The variables investigated in this study were wide-ranging and dependent on the population being tested. They included:

- For the sample population of Creative Writing students of the 2005 programme:

- The perceived importance of reading to creative writing by students;

- Student usage of libraries for study;

- Aspects of libraries, such as the collection, staff, physical space and equipment;

- Student satisfaction levels with usage;

- Students' feelings and attitudes towards libraries;

- Student needs with regards to creative writing space;

- Types of other writers' work used by students in the creative writing process;

- The type of creative writing students produced; 
- The interrelationships between creative writers, libraries and society as perceived by students;

- For the teaching staff of The International Institute of Modern Letters:

- The importance of reading to the creative writing process from an established writer's perspective;

- The emphasis placed on libraries as providers of reading resources, expert assistance and space;

- The interrelationships between creative writers, libraries and society as perceived by teaching staff;

- For the Collection Development Librarian of the Victoria University of Wellington Central Library:

- Purchase requests received from teaching staff members;

- Collection development policy within the Central Library;

- Relationships that the library has with the Institute and its staff and students;

- And the promotion of the students' creative writing work.

As this study was exploratory, it was extremely unlikely that all the variables of interest could be identified prior to the study, or all the interrelationships between them mapped out. Due to this, no specification of interrelationships between the variables could be made nor could specific working hypotheses be developed.

Those hypotheses that could be tentatively made were based on pre-project anecdotal evidence. These included:

- Most of the Creative Writing students do make use of the Class Library;

- Some students do make use of the Victoria University Central Library;

- Some of the Institute's students do use one of these libraries in preference to the other.

Each of these hypotheses could address the variables of: student perceptions of the importance of reading to creative writing; student usage of libraries for study; aspects of libraries, such as the collection, staff, physical space and equipment; student satisfaction levels with usage; students feelings and attitudes towards libraries; student needs with regards to creative writing space; the types of other writers' work used by students in the creative writing process; and the type of creative writing students were producing.

\subsection{Operational Definitions}

The following definitions clarify the usage of select terms in the context of the research. They include:

- Class library or collection: A collection of 'teaching' resources made available to students belonging to a specific discipline by their faculty;

- IIML or Institute: The International Institute of Modern Letters;

- Information need: An expressed or unconscious need for information experienced by an individual or groups of people;

- Library requirements: Information requirements that may be met through the resources of a library; 
- Creative Writing student: A student enrolled in the Master of Arts (Creative Writing) programme at Victoria University of Wellington;

- Usage: Defined by which, where and how often students use library resources;

- VUW: Victoria University of Wellington;

- Central Library: The main campus (Kelburn) library of VUW.

\subsection{Limitations and Delimitations}

There are a number of limitations that may have affected the research process that is outlined in this methodology. Initially, the sample method included the entire IIML student population, in that all students in the programme were contacted for inclusion into the survey. Survey results would allow students to include their contact details if they were willing to be interviewed, and these would be contacted to participate in a focus group interview. Purposive sampling was therefore used for the interview section of the study.

Another significant limitation was the small population size: the class had only thirty students. This might obviously result in skewed data which would have affected the descriptive statistical analysis process. The small sample size also might have influenced the results to reflect a New Zealand bias. Limitations are also attached to the small sample size from the teaching staff of the Institute and the canvassing of only one collection development librarian from the VUW Library.

\subsection{Procedures}

The methodology proposed to ensure that the research questions are addressed is of a mixed methods nature. As there is no prior research in this area of study, the proposed use of concurrent triangulation mixed methodology will help to better understand the outlined research problem by converging both quantitative and qualitative data. In the study, a survey will be used to determine the usage of the class library by the students and to identify the information needs of the Master of Creative Writing students and factors influencing usage. At the same time, the information needs of the students will be explored and further elucidated through student interviews at the International Institute of Modern Letters. To identify whether these needs have been recognised and targeted by the VUW libraries network, collection development policy documents that are publicly available will be examined.

Although it is implicit, it is useful to state explicitly that this study has a delimitation in that it is intended to focus on Masters level students enrolled in the Master of Creative Writing programme at Victoria University of Wellington.

\subsubsection{Populations and Samples}

The research was principally aimed at two populations: the first group was the students of the Creative Writing Masters programme; the second was the staff of the Institute. It was intended, due to the smallness of these populations, that all of the students would be surveyed, and that then a non-random sample of students who had indicated that they were willing to be involved in the second stage would be

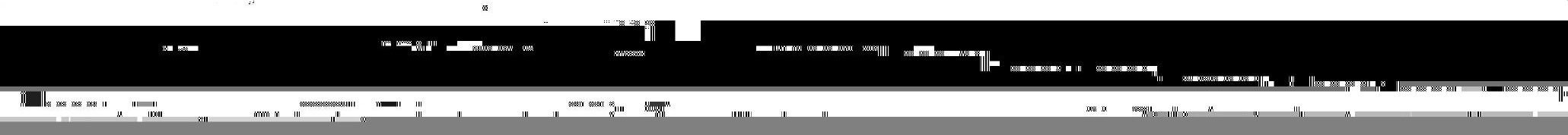


interviewed. The staff of the Institute is small, and it was the researcher's intent to interview all those who indicated a willingness to be involved in the project.

A third population was also added, that of the Collection Development Librarian, when it was discovered that there is no current collection development policy in place to indicate how the VUW Library went about identifying and meeting the information needs of Creative Writing students.

Participation in the project occurred at different levels and at different times for the three 'groups' throughout the timeline of the project:

- Students:

○ The previous year's (2005) students would be surveyed and interviewed in the course of the study;

o Future students would benefit from:

- Implementation of recommendations based on findings;

- Collection development policies that reflect a better understanding of the information needs of Creative Writing post-graduate students;

- And a better understanding in the ways in which reading may contribute to their development as writers.

- Institute teaching staff:

- Would be interviewed in the course of the research to identify how libraries might contribute to meeting creative writing information needs and to identify other ways that they may contribute to the creative writing process;

- Would benefit in being able to contribute to the decision regarding retention or integration of the library based on the research findings.

- The Collection Development Librarian of the VUW Central Library:

- Would be interviewed in the course of the study to gain an understanding of how the Central Library identifies and meets the students' information needs;

- Would benefit from developing a better understanding of Creative Writing students, their information needs and how these could be better met.

\subsubsection{Research Instrumentation and Analysis}

The planned research process (see Figure 2) outlined the intended procedure, whereby the student survey would be developed with guidance from the current literature and by Institute staff, and comprised of predominantly quantitative questions utilising Likert scales with additional open-ended questions to satisfy the qualitative component of the survey. Thus the data garnered would be either nominal (where students could choose more than one choice in a question), ordinal (where students had one choice only) or qualitative. In practice, the questionnaire was developed with guidance from only the literature reviewed due to difficulty of organising staff interviews in time. The questionnaire was piloted to ensure that it was easily understood with no ambiguous questions or terms used. 
Figure 2. $\quad$ Project Mixed Methodology Flow-Chart*

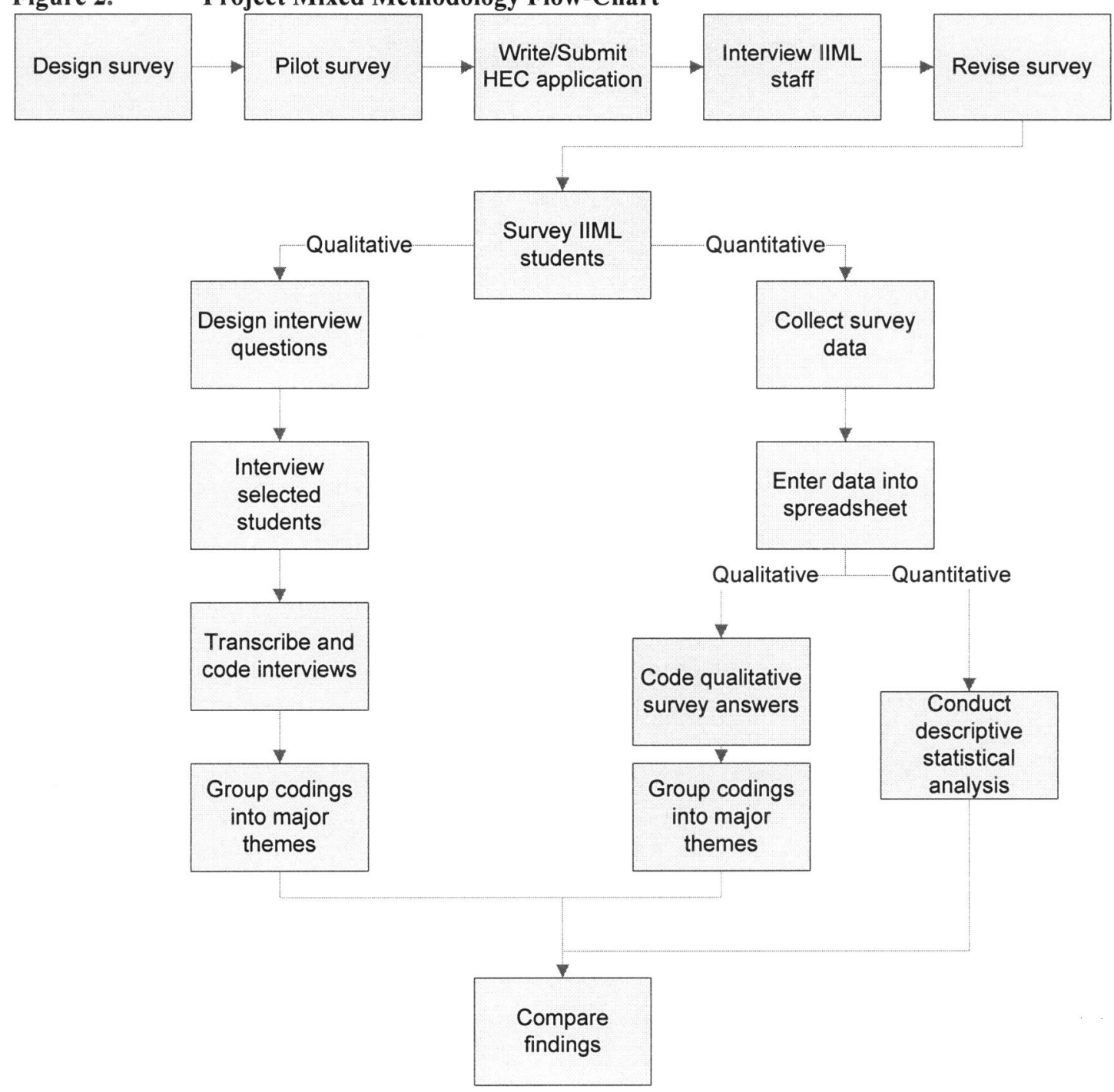

The survey questions were focussed on meeting the objectives outlined above (see Section 2) with regards to library usage, identification of users' information needs, and factors that influence the Institute's class library usage.

The survey data was to be collated and the quantitative data subjected to descriptive statistical analysis. With such a small sample size (no more than thirty respondents), inferential statistical analysis would not be useful in this instance. The qualitative data gained from the survey would be coded and then grouped into major themes; these could be used to help guide the development of interview questions for those chosen for the student interview section of the study.

The student interviews (see Appendix C) were focussed on further exploring students' information needs and influencing factors that persuaded students to use the Institute class library in preference to other available library resources. The interviews were also used to contextualise the importance of reading to students' creative processes and the relationships with which they engaged with libraries and society. The

\footnotetext{
${ }^{*}$ HEC - Human Ethics Committee
} 
interviews were to be conducted as focus groups and were to be taped for later transcription.

Coding of the transcripts and grouping into major themes would allow for comparison between qualitative data and quantitative data, thus ensuring that any strong correlations or divergence could be noted and discussed in the findings.

Staff interviews (see Appendix D) were intended to cover similar issues to those addressed in the student interviews, and would also extend to teaching practices at the Institute. Coding of transcripts would reveal if their were any similarities between IIML staff and student opinions regarding the importance of reading and the other factors outlined above (see Section 2).

The interview with the Collection Development Librarian (see Appendix E) would follow a similar procedure to those of the Institute's staff and students but with a different emphasis in the questions, specifically how the Central Library goes about meeting student information needs.

\subsubsection{Time Schedule}

The project was be broken down into three phases: research preparation; data collection and analysis; and report synthesis (see Appendix A for the proposed project Gantt chart). The end date of each phase was considered as a milestone by which to monitor progress throughout the project. The timeline over which the project was to be conducted was intended to run from 17 January 2006 to 22 May 2006.

The planned research preparation phase spanned almost five weeks (see Gantt chart) and included the following activities:

- Writing those sections of the final report that are not dependent on the collection of data, such as the literature review, the introduction, the methodology sections and so on;

- Designing, piloting and revising the study, ready for posting out to students when the project proposal is accepted;

- Writing and submitting the HEC application to the committee for review;

- Interviewing Institute staff; transcribing and coding those interviews;

- Setting up spreadsheets in SPSS for ease of data entry and statistical analysis;

- And undertaking administrative preparation to ready the survey for posting to students.

The data collection phase, which was of a similar length to the preparation phase, included:

- Posting out the surveys with a self-addressed envelope for returning them;

- Data entry of the returned surveys as they came in;

- Development of interview questions from qualitative answers to open-ended survey questions;

- Setting up, conducting, transcribing and coding the student interviews;

- Sending out reminder letters with a second copy of the survey to nonrespondents; 
- Contacting VUW Central Library staff who manage collection development policies regarding documents relating to meeting the information needs of Creative Writing Masters students (this was later changed to organising and conducting an interview with the Collection Development Librarian);

- Final collation of all returned surveys and coded transcripts;

- Conducting descriptive statistical analysis on the quantitative data and drawing major themes out of the qualitative data.

- Findings were then all brought together for comparison:

- To see what patterns could be found;

- And to determine if any discrepancies resulted between survey data and the interview data

The final phase was for report synthesis, and two weeks was allowed for this. The time would be used to draft the final report and for writing the final report with any attendant recommendations. This final report was then to be submitted for assessment on the 22 May 2006. If more time was needed, due to any unforeseen delays in the research process, there would be three further weeks available before the final duedate of the 12 June 2006.

\subsubsection{Ethical Obligations}

To support ethical practices in research undertaken at the Victoria University of Wellington, there is a Human Ethics Committee (HEC) to which all researchers who use human participants in their research must make an application before they may conduct any research at all. This is to ensure that no participant in any research undertaken at the university is subjected to unethical research practices.

It was intended that the HEC application for this project would be in two stages, the first addressing the IIML student questionnaire, and the second addressing the interviews with Institute students, teaching staff and with the VUW Central Library Collection Development Librarian. Each of these 'interview groups' was provided with a different information sheet. Students were informed that their privacy would be kept (non-disclosure of names in report), while staff and the Collection Development Librarian were informed that responses made by them would be attributable. On conclusion of the research and acceptance of the project report, all data collected throughout the course of the research, including interview tapes and transcripts, would be destroyed within two years, in accordance with HEC application guidelines.

\section{Data Analysis and Interpretation}

Collection of the data, both quantitative and qualitative, did not occur concurrently as was specified in the procedures. There was difficulty in organising IIML staff interviews, and because of tight time constraints the questionnaire went ahead prior to the conduction of the interviews. This changed the methodology from a concurrent to a sequential mixed methods approach. However, convergence in the data was still able to be identified. The flow of the timeline was followed, but not rigorously. 


\subsection{Questionnaire}

There were seventeen respondents to the thirty questionnaires that were mailed out. The response analysis is broken down into the aspects addressed in the questionnaire instrument.

\subsubsection{Reading, Libraries and the Creative Writing Process}

The first question in the questionnaire asked Creative Writing students what they took from reading other writers' works. All of the Creative Writing students who responded to the questionnaire answered this question and the four main themes that were touched upon were:

- Reading for pleasure;

- Reading to better understand writing styles and techniques and being able to use other writers' works as models;

- Reading for factual research and for reference; and

- Reading for inspiration.

Participants noted that what they took from reading could sometimes be dependent on the type of writing in which they themselves engaged. One student, for example, noted that, as a screenwriter, "...the books I borrowed were almost all 'how-to's on screenwriting."

The majority of those surveyed used other writers' work as models of specific styles or techniques and so it could be inferred that a problem that induces the creation of an information need in Creative Writing students could be the lack of specific models of writing in their knowledge base.

The importance of physical space in which creative writers work was the subject of question 2, which asked students where they wrote. All the students surveyed (17) either wholly or partially produced writing at home. Second in preference were rooms provided by the Institute (writing rooms or the Class Library), but only five students of those surveyed used these. A few students responded that occasionally they wrote in places like cafes, the train or bus, or at the beach. Only one student respondent wrote while in the VUW Central Library.

This preference for working creatively at home may be based on a number of factors and is more closely examined in question 4.

The next question (question 3) asked survey participants what type of writing they mostly produced. The students who returned the questionnaire, for the most part, produced only one type of writing: often this was poetry, although a few wrote novels, plays or screenplays. Very few wrote non-fiction, such as essays or memoirs. Some students did, however, write a range of material: “...during the year I also wrote poetry, short stories, articles/columns for websites and many, many pages in my personal journal."

The type of creative writing in which a student is engaged might have a profound effect on the student's information needs, in that the lack of specific models of writing 
in their knowledge base would be specific to the type of writing that they produced. This was explored further in questions 6 and 7.

Question 4 was used to determine what students felt made the optimal creative writing space for them. The main factors that create an optimal writing space for students (see Figure 3 ) include a computer (16 respondents), a desk or work table (12), books and other reading material (11), privacy (10) and lots of light (10). Fifteen of the seventeen survey respondents also required other factors in their writing space in order for them to work at their best.

Figure 3. Factors Students Needed in Their Writing Space

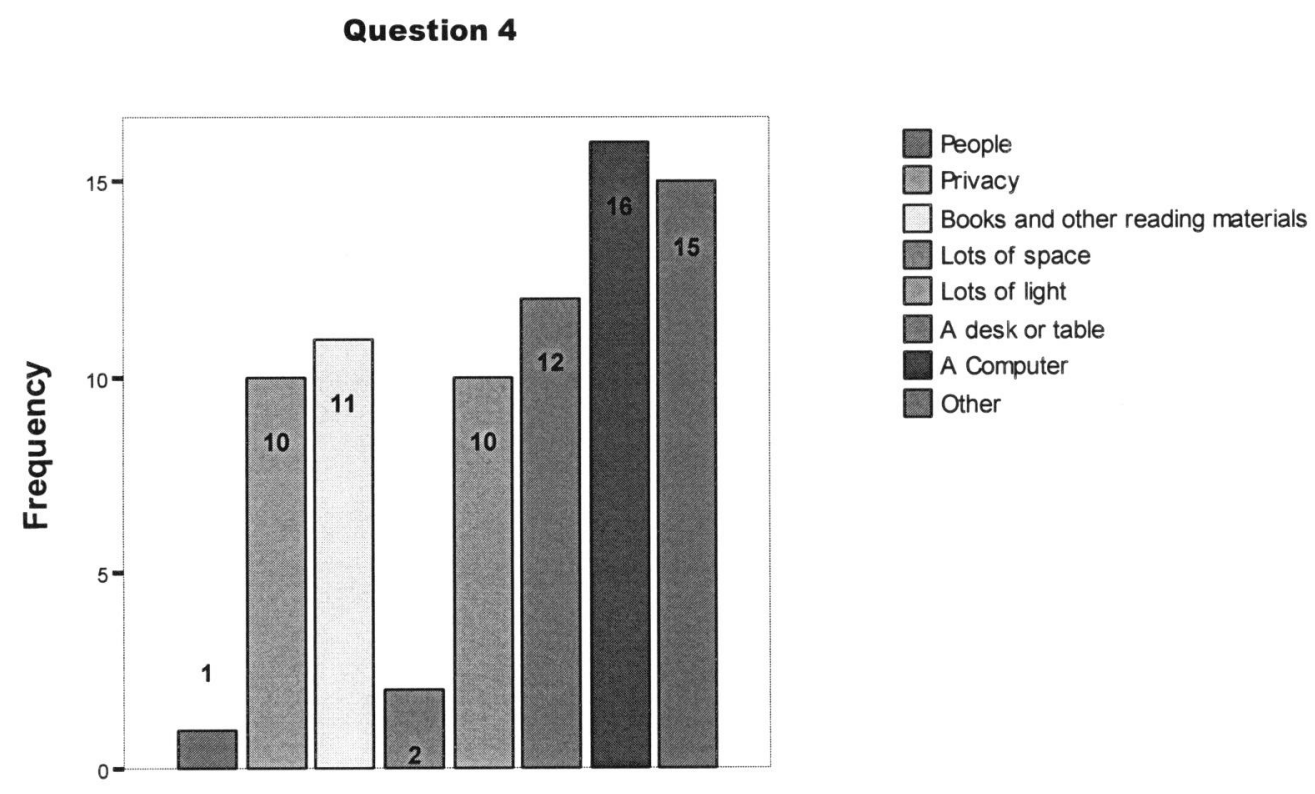

Factors students needed in their writing space

These other factors included:

- Stationery and printers;

- Access to the Internet;

- Background music;

- Quiet;

- Access to kitchen facilities;

- Comfortable furniture; and

- Spaciousness (one student said they used the space to plan story arcs).

Two of the factors included in the questionnaire had poor response rates: people (for background noise, support and so on); and lots of space were not indicated to be of great importance in the creative writing space of those surveyed.

The common factors students preferred in their writing space as well as the range of other factors they felt were required do relate to student responses to question 2 , in that the majority of these are easily controlled in the students' homes. Those factors relating to personal comfort are of significance here. 
The next question (question 5) was used to determine how frequently students made use of other writers' work when they wrote. The majority of those surveyed responded to this question, with over half ( 8 of 15$)$ stating that they did not very often make use of others' writing when they wrote (Figure 4). Six students said that they did use other writers" work "often" when they were writing, and one student "quite often."

All fifteen respondents to this question did, to whatever extent, make use of others' writing when they wrote. In addition, one student noted beside the question on the questionnaire form that they read, "... other writers work all year but... didn't 'use' them when... [they]... wrote".

The frequency with which creative writing students make use of other writers' work may be a reflection of the type of creative work in which a student writer is engaged. Some modes of literary expression, for example a historical narrative, may require more research than others. This highlights another problem that may develop into an information need for a student. When researching, especially for historical context, creative writers will frequently not have a comprehensive and detailed understanding of historical language, costuming and so on, and this results in a knowledge gap.

Figure 4. Students Use of Other Writers' Work

\section{Question 5}

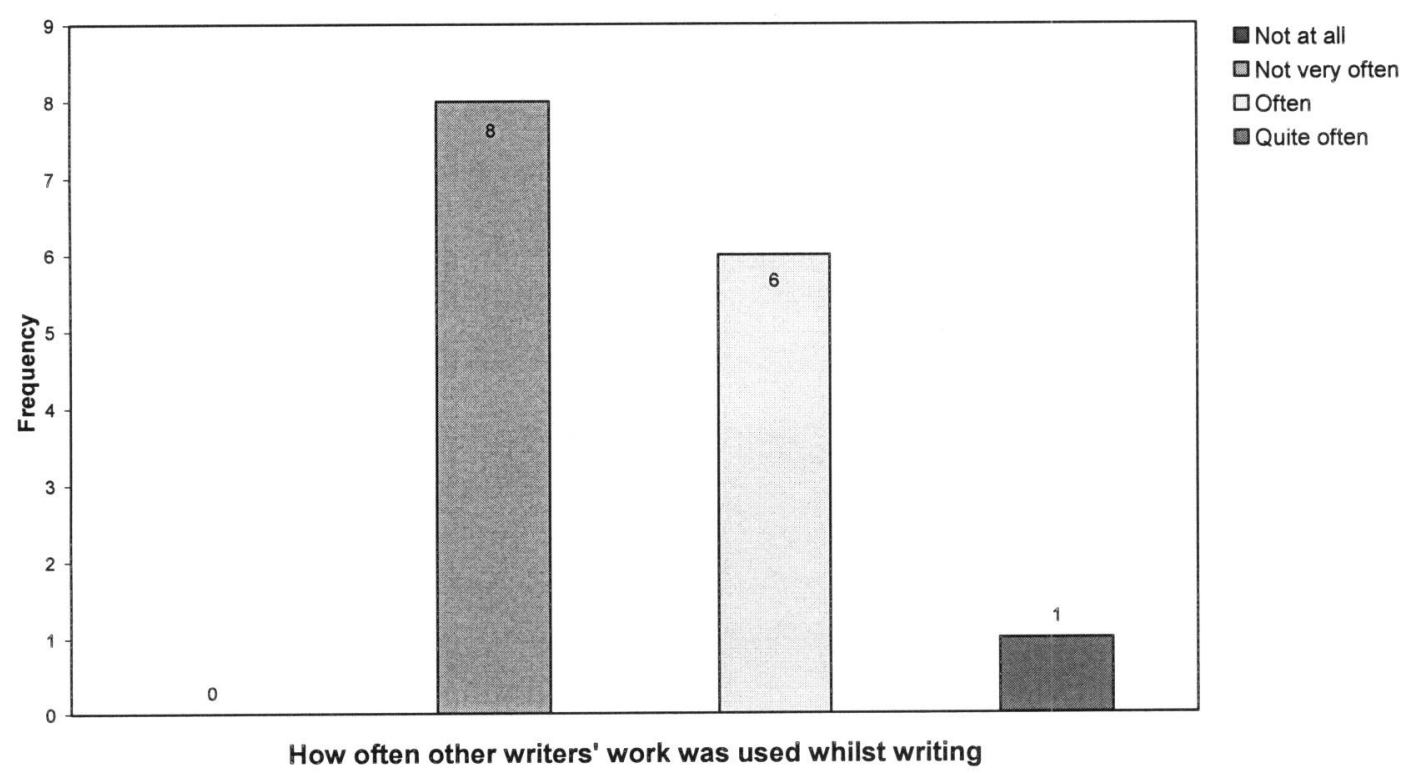

Question 6 of the questionnaire asked students how they made use of other writers' work when they wrote. Those students surveyed used other writers' work in their writing in a range of ways:

- Some students used others' writings as examples of style and technique;

- Some employed them for research for the setting or minutiae of their writing;

- Some used others' works specifically as a style guide or as sources of quotes; and

- Some used the works of other authors to "inspire," or as an escape from writing themselves. 
One student noted that they used other writers' works to provide material to which they could respond for their reading journal (although all students were required to keep a reading journal). Another student used others' writing purely for comparison: "[use of other writers' work was] purely comparative - I tried to distance myself from it so I wasn't emulating a writer/group of writers."

Here again are examples of students meeting their information needs, and so the underlying problems that prompted these needs are revealed. Although the first three factors identified in this question could easily fit into the model of problems that provoke an information need in students, it is harder to determine whether a need for inspiration could fit into this model.

The following question asked "what type of other writers work did you use when you wrote?" Students used a wide range of others' written material when they wrote (see Figure 5). These are ranked by type in order of frequency:

- Poetry (12);

- Novels (9);

- History and Short Fiction (8);

- Humanities (7);

- Arts (6);

- Writing Style Guides (5);

- Science and Geography (3);

- Music, Religion and Plays (2); and

- Technology (0).

Figure 5. Type of Other Writers' Work Used

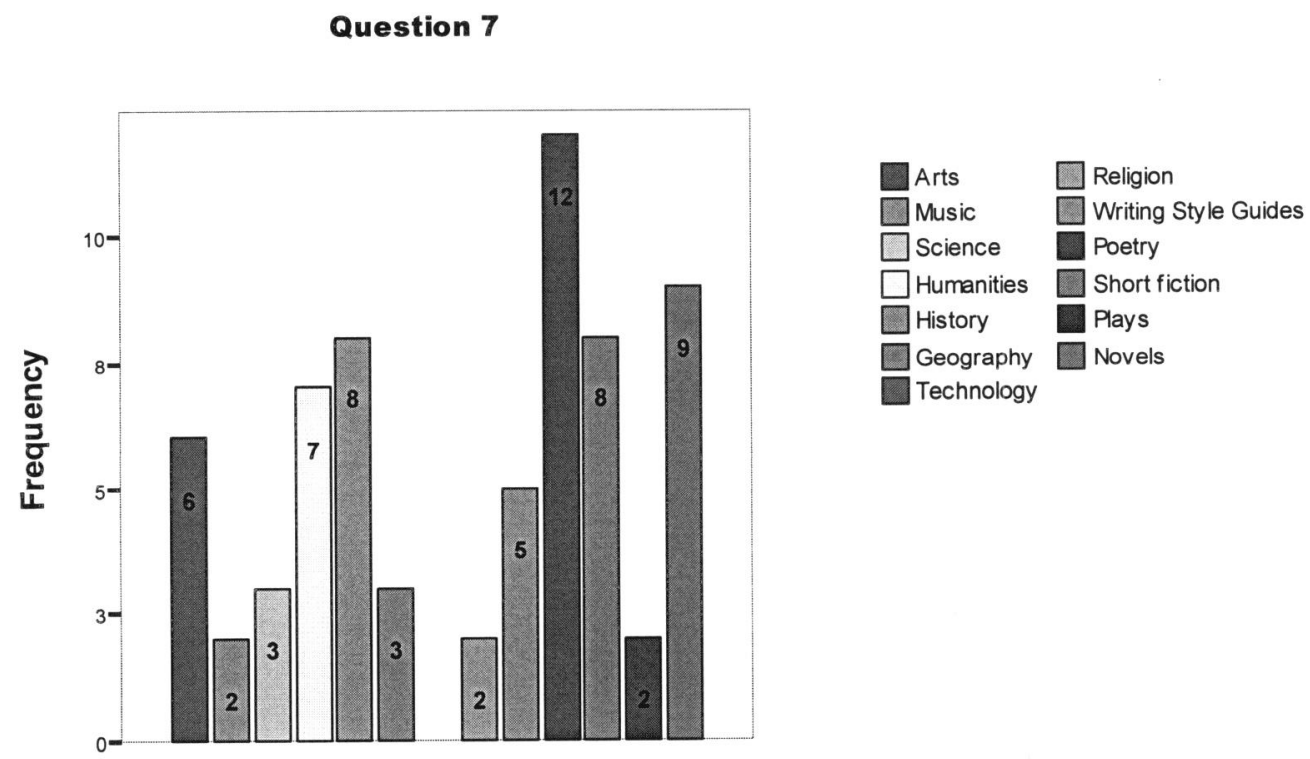

Type of other writers' work used by students

In the figure above (Figure 5) it is clear that poetry and novels are the most frequently used. This partially matches the prevalence of poetry writers in the respondents to the 
questionnaire as identified in question 3. It can be seen that the majority of other writers' material that is used is, itself, literature and maybe used as a guide or model, or for inspiration. In comparison, the bulk of the other material used by student writers is to help flesh out and contextualise their writing: it is material used for research.

This provides further support to the idea that the type of writing that a creative writer producers can have an effect on the type of other writers' work that they use.

Additional types of other writers' works used by students was explored in question 8 . Seven of the survey participants responded when asked if there were any other types of other writers' works, not stated in question 7, that they made use of when they wrote. Those types of works respondents referred to included:

- Memoirs and biographies;

- Essays;

- Journals;

- Literary reviews;

- Interviews with poets;

- Screenplays; and

- Cookery books.

This may tie into what students would like to see in the IIML Library (see question 13). It can be seen (from the responses students made to questions 5, 6, 7 and 8) that reading, of their own work and others, is an integral part of the creative writing process of the Creative Writing students. So meeting this need for written resources is of importance not only to students, but also to teaching staff as well as the staff of Victoria's Central Library.

This finding agrees with what creative writers articulated in papers included in the literature review (see Section 1.2.4).

\subsubsection{Library Usage}

Of the students who answered the questionnaire, sixteen found some of their reading material in the Institute's Class Library (see Figure 6). Other ways in which students sourced their reading material included, in order of frequency:

- Their own personal collection (14);

- A public library (14);

- The VUW Libraries (12);

- Their friends, family, and so on (10);

- Other providers (7). 
Figure 6. Sources of Students' Reading Material

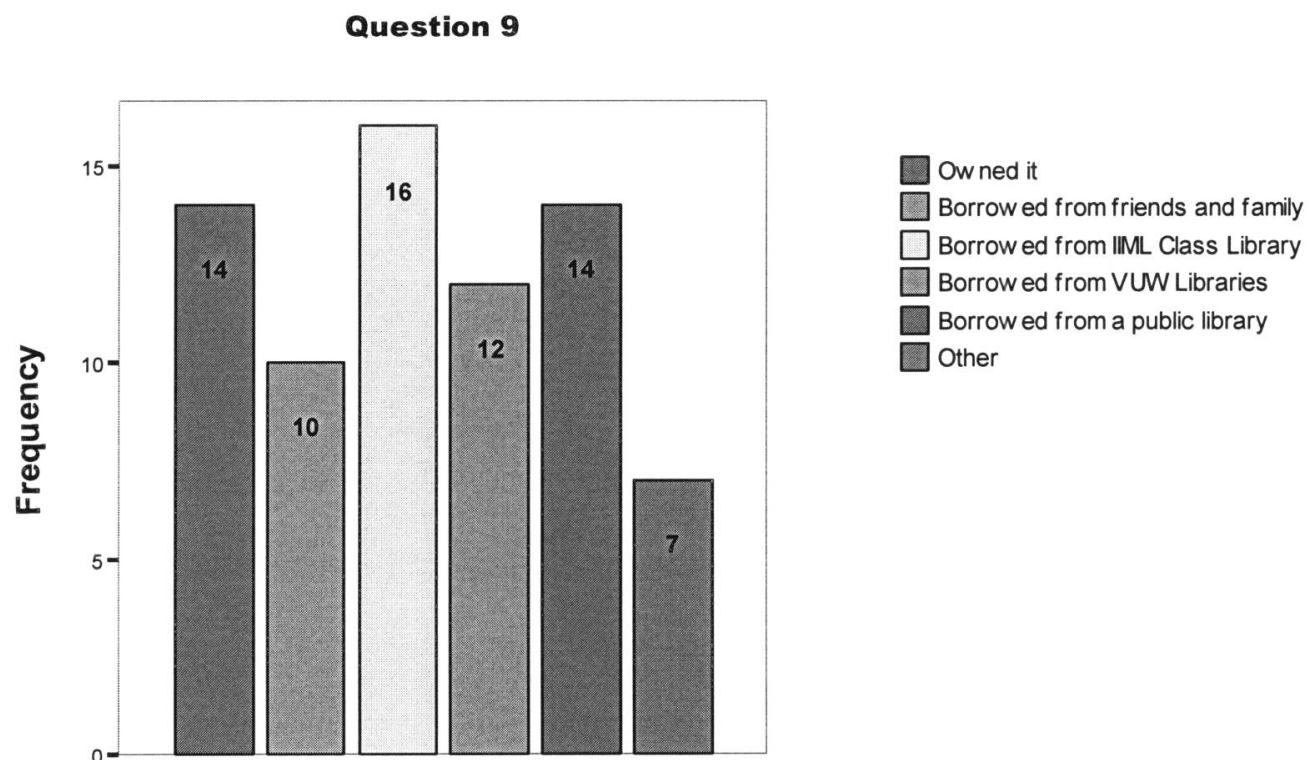

Where students found the material they read

Other ways in which respondents accessed reading materials included:

- Accessing through the Internet;

- Using libraries other than those specifically stated in the questionnaire;

- Buying their reading material as they needed it; and

- Receiving it in class or from their classmates.

The clear predominance of use of the IIML Class Library may easily be a reflection of the proximity of the library to a major learning space of the programme and its accessibility for the students. Other factors might also influence students' usage of the Class Library, and these are explored below.

Respondents were asked what general features of those libraries that they used encouraged them to use them. Nearly half of the students that responded to the survey said that easy access to the libraries was important; six students cited ease-of-use as being important. Nearly half of all students said a good-quality collection with a diverse and well-developed range of reading material available was essential.

Five students said that being able to find the material on the shelves and it being readily available for issuing was important. Some of them cited examples of when this wasn't the case: "so many VUW books missing!! (I would say $1 / 2$ the stuff that was available on the catalogue I couldn't find on the shelf."

Only one student said that a user-friendly environment and relevancy of the material to the course were important features of the libraries they used. Physical features such as seating, a useful catalogue, long issuing period, helpful staff and useful library services (such as interloan) were also mentioned as general features of those libraries that they felt encouraged to use. 
All of these factors act as intervening variables in the information search process of Creative Writing students. When students try to meet their information needs, these factors can determine where they will go to meet it.

In question 11, students were asked if they used libraries other than, or in addition to, the VUW Central Library; they were also asked what these other libraries offered that encouraged them to use them.

The predominant reason for those students surveyed making use of other libraries in addition or in preference to the VUW libraries was because the VUW collections frequently did not have the resources that respondents required. Students' perception of the low accessibility and poor quality of the VUW Central Library collection, as well as the location of the library, were also factors that affected respondents' use of the VUW libraries and act as intervening variables in the information search process.

Question 12 was used to determine the frequency with which the Creative Writing students made use of the Institute's Class Library. Most students (10 of 17) surveyed made use of the library at least once every fortnight (see Figure 7). The remainder of the respondents made use of the library about once a month.

Figure 7. Student Usage of the IIML Class Library

\begin{tabular}{|l|c|}
\hline \multicolumn{1}{|c|}{$\begin{array}{c}\text { How often did you use the IIML } \\
\text { Collection? }\end{array}$} & Frequency \\
\hline 2 or more times/Day & 0 \\
Once/Day & 0 \\
Twice or more/Week & 2 \\
Once/Week & 1 \\
Once/Fortnight & 7 \\
Once/Month & 7 \\
Never & 0 \\
\hline
\end{tabular}

Fifteen of the Creative Writing students surveyed had diverse suggestions on how the Institute's library and its collection could be improved (question 13, see Appendix B). These included adding to the IIML collection more:

- Scripts and plays;

- DVDs of magazine collections (e.g. The Complete New Yorker);

- Poetry (by both New Zealand and international poets);

- Magazines, journals and articles;

- Fiction, both New Zealand and international publications;

- Craft and theory texts;

- Non-fiction;

- Interviews, memoirs and biographies;

- Short stories;

- Reviews; and

- Publications by MA (Creative Writing) graduates.

Another suggestion included providing the collection with an electronic catalogue and providing students with library services: "It would have been good to have a list of the 
books in the library that we could access from home and a way of reserving a particular book."

There was no strong correlation in the responses, but they do help to identify the perceived deficiencies in the existing collection. These deficiencies could also act as mitigating variables of library usage. If the Institute were to address these deficiencies, in the case of the collection being retained separately, then it could follow that they would better meet the information needs of their students.

The following figure (Figure 8) plots the frequency with which the Creative Writing students made use of the library collections commonly available to them at the time that they were studying.

Figure 8. Student Usage of Various Library Collections

The Frequency with which Students Made Use of Library Collections

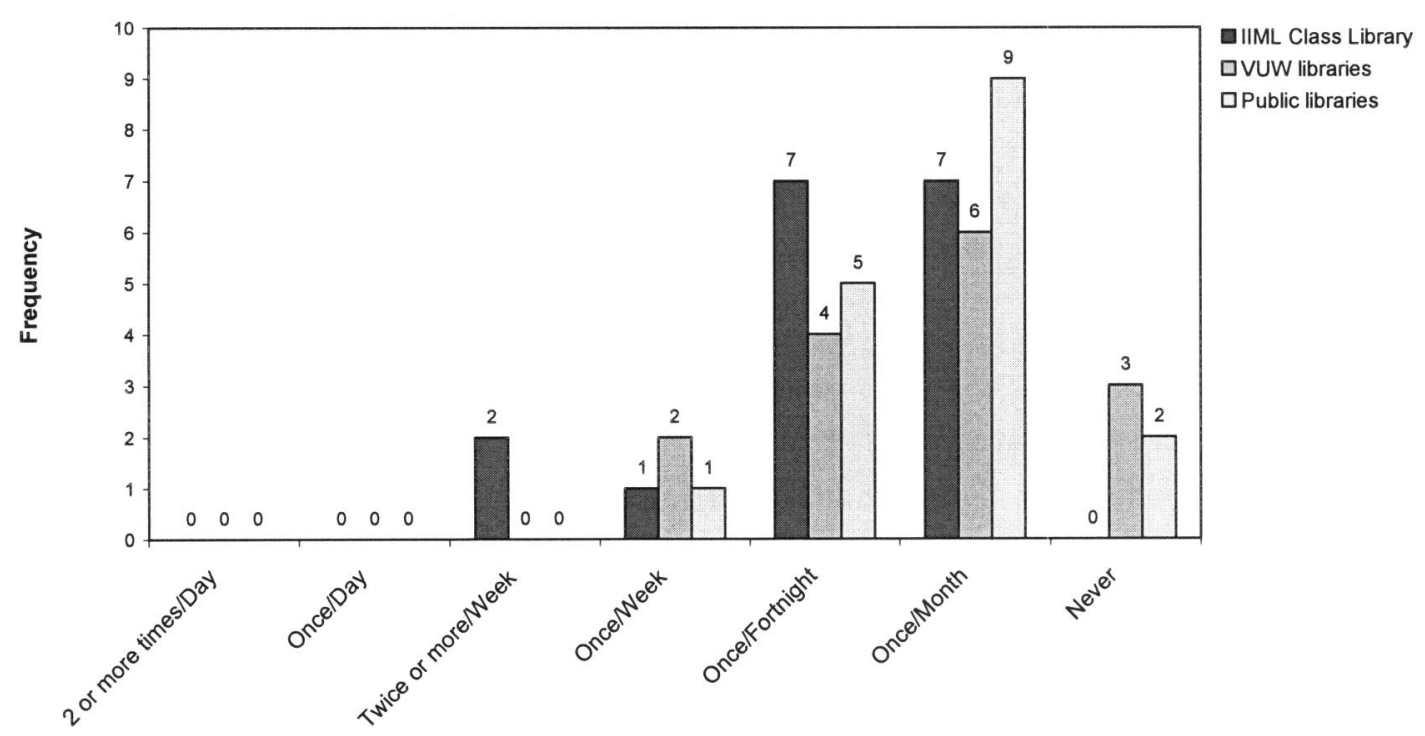

Most respondents made use of the Victoria University Libraries while they were studying towards their MA (Creative Writing): some of them visited the libraries once a month (6); others visited once a fortnight (4); or once a week (2). Three students surveyed never used the VUW Libraries. Two students noted beside the question that they, at most, used the VUW Central Library two or three times during the study year.

The frequency with which those who answered the survey made use of public libraries is also included in the figure above (Figure 8). Of those surveyed, two did not make use of the public libraries to which they had access. The majority of students did make use of them, however, and visited the public libraries about once a month (9). Five students visited public libraries once a fortnight; one student visited about once a week.

Of those libraries to which students had access, they made most frequent use of the International Institute of Modern Letters Class Library, followed by public libraries and, lastly, the VUW Libraries. This, most likely, can be interpreted to be a reflection on the factors identified in questions 10 and 11 and how the IIML Class Library is 
better able to meet the information needs of the students in comparison to other libraries.

The predominant factors that govern the variance in usage of the libraries would most likely be: the accessibility of the collection; its convenience to the students' place of study (some students commented that they 'frequently' browsed the Institute's collection while waiting for class); as well as familiarity with the collection. These factors are further explored in the responses to question 26.

The findings here for library usage are indicative of how the information search process can be affected by external variables relating to the information providers.

\subsubsection{User Satisfaction}

The next section of the questionnaire aimed to determine respondents' satisfaction with various features of both the Class Library and VUW Central Library. The results for this section are paired to allow for comparison between the two libraries (barring question 19 which addresses respondents' satisfaction levels with VUW Central Library staff).

Figure 9. Satisfaction with Two Library Collections

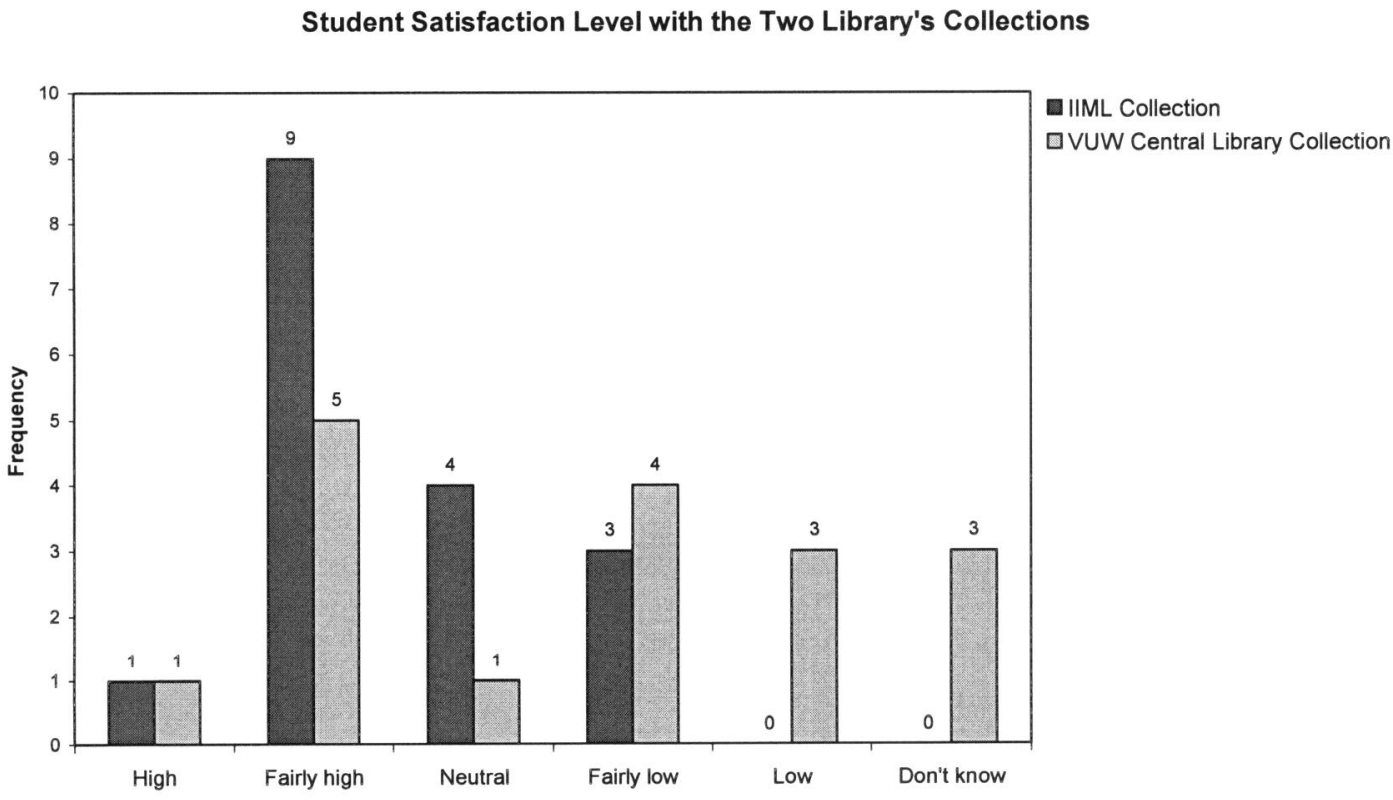

The figure above (Figure 9) shows that the majority of those survey rated their satisfaction level with the collection of the Institute's Class Library as 'fairly high' (9) to 'high' (1). Four students rated their satisfaction level as 'neutral' and three students as 'fairly low'. One student commented that the collection as it stands was not comprehensive, and was "just a gesture at the moment."

More respondents rated their satisfaction level with the collections within the VUW Central Library as 'fairly low' (4) to 'low' (3) than 'fairly high' (5) to 'high' (1), but only marginally. Two students had further comments to make about the VUW 
collections: one said that though they had good art books, their contemporary fiction collection was "really bad" and out-of-date; the other noted that the accessibility of the collection was "low."

This compares somewhat negatively with the satisfaction levels of students with the collection of the Institute, and is possibly a result of factors already discussed above in Section 3.1.2 that will be further elucidated in the interpretation of the data for question 26.

Figure 10. Satisfaction with the Physical Space of Two Libraries

Student Satisfaction Level with the Physical Space of the Two Libraries

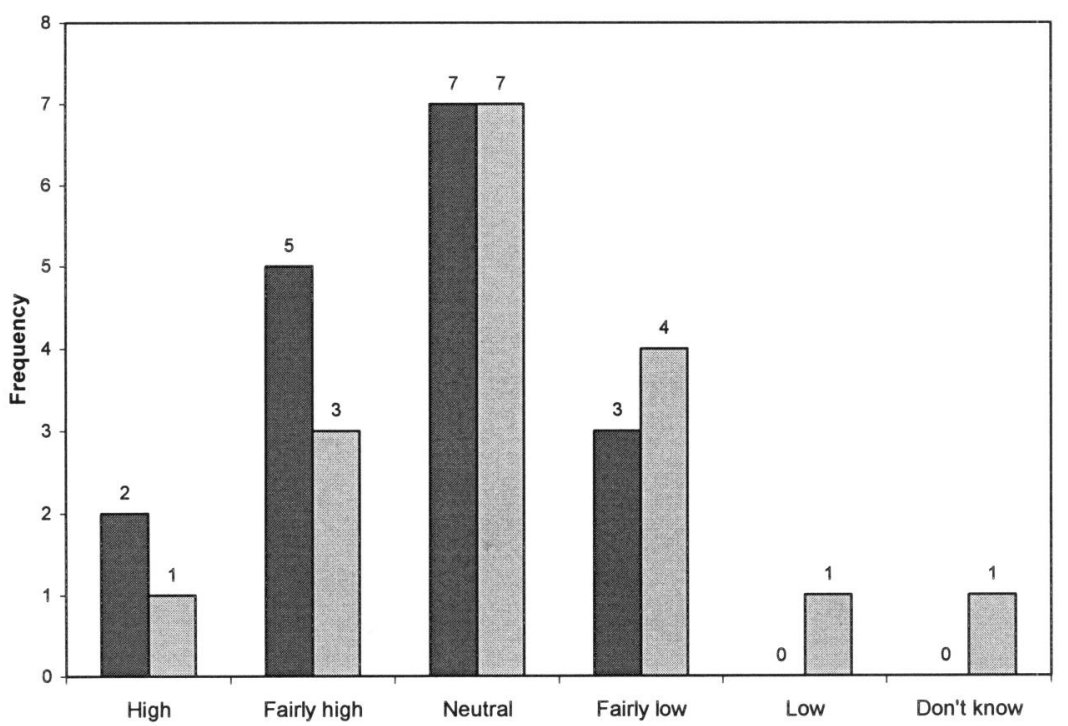

- IIML Library Room

口VUW Central Library Building

Seven of the seventeen student respondents rated their satisfaction level with the physical space in which the collection of the Institute is housed (see Figure 10) as "neutral." Seven respondents rated it as "fairly high" (5) to "high" (2), while three students rated it as "fairly low." The same student who commented on the comprehensibility of the collection in the above question noted that there is limited space for expansion of the IIML collection - an important factor in determining whether the collection should be integrated into the VUW Central Library.

As can also be seen from figure 10, four students rated their satisfaction levels with the VUW Central Library Building as "fairly high" (3) to "high" (1). Seven respondents rated their satisfaction levels as "neutral"; five as "fairly low" (4) to "low" (1). One student commented that the view from the Central Library Building was good.

In comparison with the physical space in which the Institute houses its Class Library, students rated their satisfaction levels with the VUW Central Library building lower. 
The third aspect of libraries which the questionnaire surveyed students about was the "equipment" inside the libraries (questions 18 and 22). Equipment, in this sense, means the computers, the student computer network, the catalogue or issuing file, photocopying machines, and so on. Students rated their satisfaction levels with the equipment provided by the Institute's class library, for the most part, as "neutral" ( 9 ; see Figure 11 below). Only two students rated their satisfaction level as "fairly high." Five students rated their satisfaction as "fairly low" (3) to "low" (2). One student responded with "don't know."

One student commented that the card catalogue of the Institute is not used properly and so books stay out "forever." Another student noted that other students seemed to have problems while using the computer in the Class Library, and that this put them off.

For the VUW Central Library, students rated their satisfaction level with the "equipment" it provided as follows: Five as "fairly high"; six students as "neutral"; and one as "fairly low." Five students could not rate their satisfaction level with the equipment of the VUW Central Library, mostly likely because they did not make use of it, although one of these five students commented that the one piece of equipment she used in the Central Library, the stapler, had many problems.

When compared, the users of the VUW Central Library were more positive about the equipment it provided than they were of that provided by the Institute's Class Library.

Figure 11. Satisfaction with the Equipment of Two Libraries

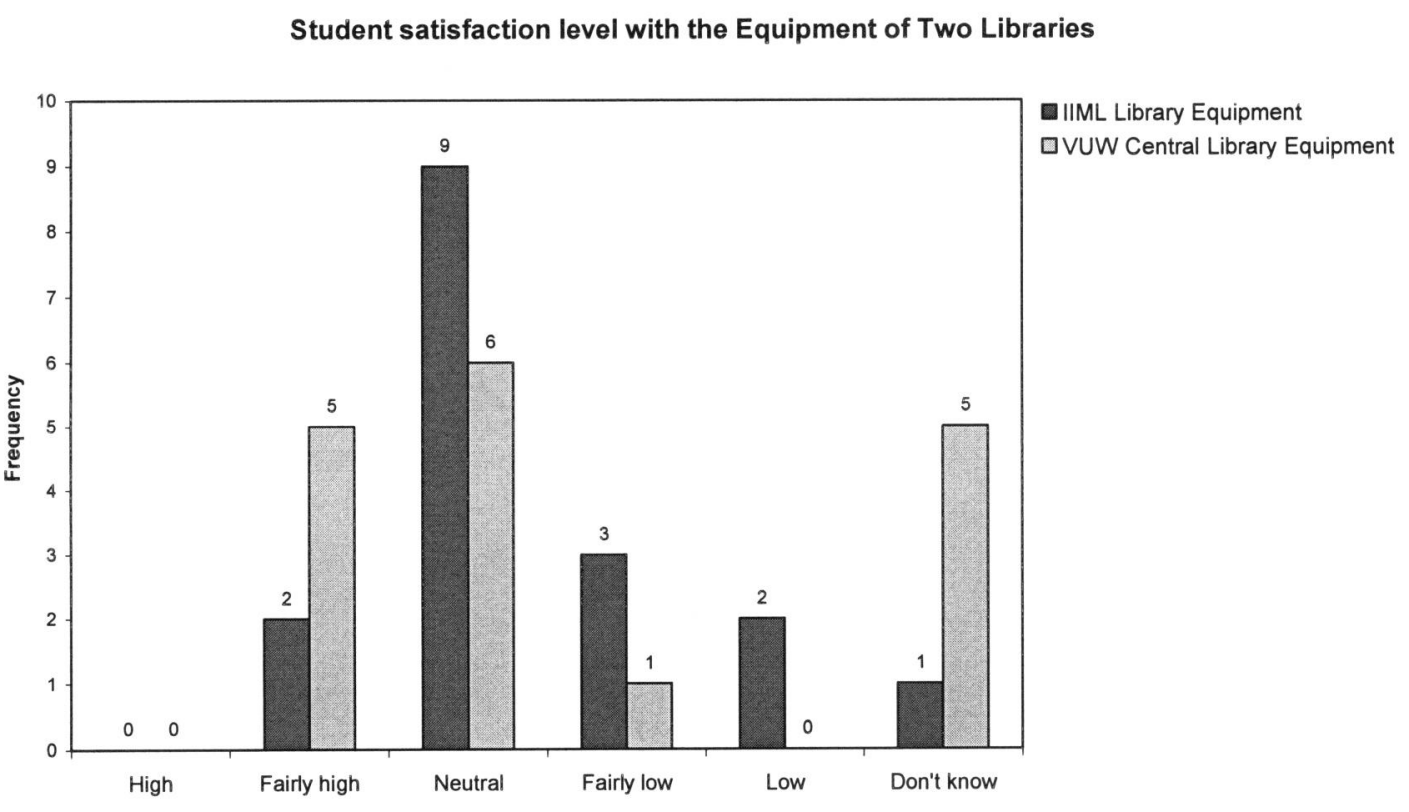

Question 19 asked the respondents to rate their satisfaction levels with the library staff they encountered in the VUW Central Library, and these are shown in the figure below (Figure 12). Five students rated their satisfaction level as "fairly high" (3) to 
"high" (2); seven as "neutral"; three students as "fairly low" (2) to "low" (1); and two students responded with "don't know."

The strongest-rated level of satisfaction here is neutral, but the students responded relatively more positively than not. How this satisfaction level affects their usage of the library is unknown and is an aspect which may fuel further research.

Figure 12. Satisfaction with the Staff of the VUW Central Library

Student satisfaction level with the library staff of VUW Central Library

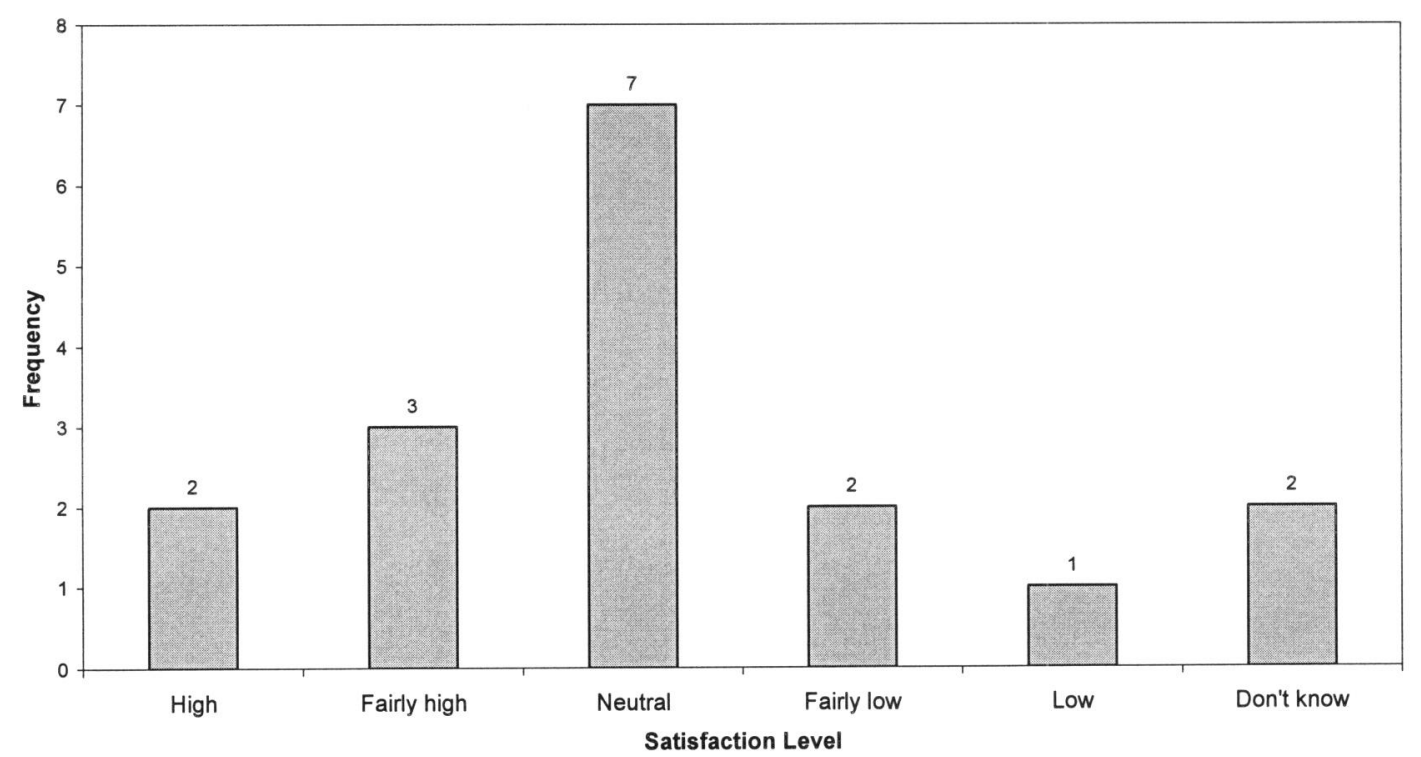

Overall, it would seem that students are, relatively, more satisfied with the Institute's Class Library than with the VUW Central Library, and is demonstrated in their comparative usage of each library. This may also reflect how well each library is meeting the information needs of each student. In better meeting the information needs of students, it could be further posited that the IIML library facilitates the information search process more than the VUW Central Library. 


\subsubsection{Libraries and Their Effect on How You Feel}

The next three questions of the survey $(23,24$ and 25$)$ endeavoured to discover what effect various libraries had on students and how they felt when they used them.

Figure 13. Affective Responses to the IIML Class Library

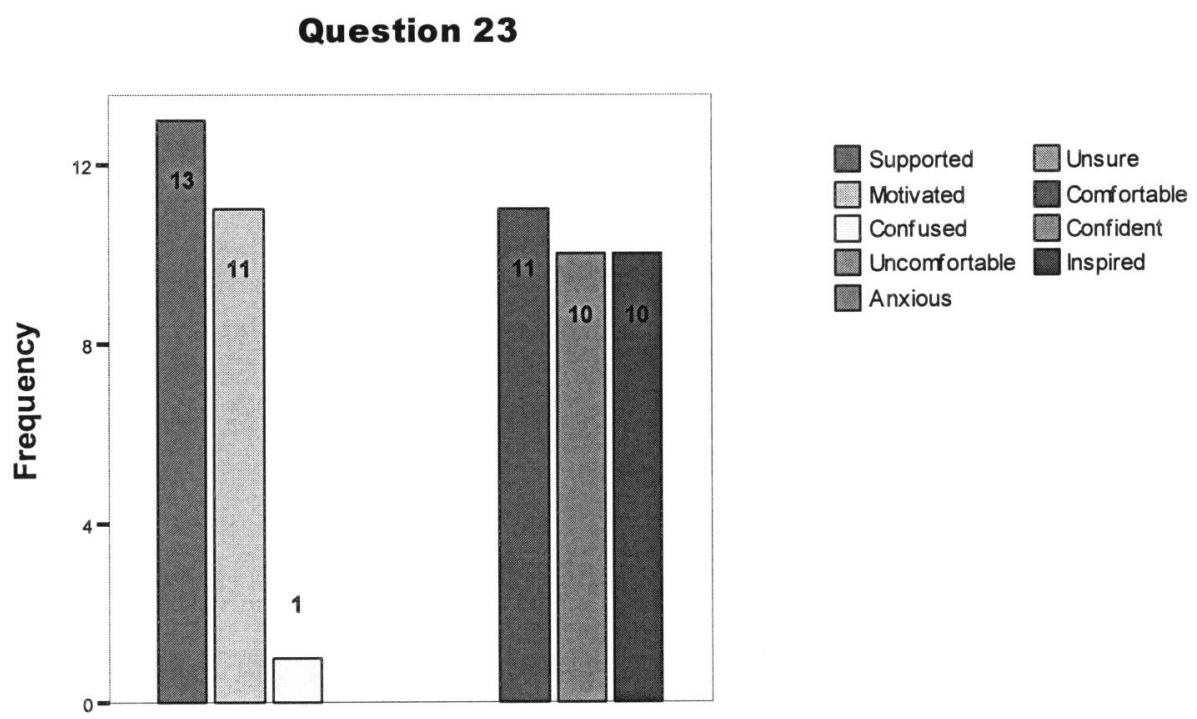

Feelings experienced by students when using the IIML Class Library

The graph (see above, Figure 13) of student responses to the question of how they felt when using the Institute's Class Library shows that students felt, predominantly:

- Supported (13);

- Motivated (11);

- Comfortable (11);

- Confident (10); and

- Inspired (10).

All of these strong responses are positive; only one student had a negative response, "confused," and this was included with the positive feelings they also experienced when using the Class Library.

The absence of negative feelings experienced by students using the IIML Class Library makes it unlikely that students experience any degree of library anxiety here. This is not unusual; most studies that address library anxiety look at academic library users and the atmosphere of the Class Library is a mismatch for that of most academic libraries.

Further supporting this idea, one student noted beside this question that, although they didn't know what was there, they felt it was a pleasant place to browse and that it was "their" space. In providing a special collection for the use of its students only, the Institute has granted them an environment that invokes positive feelings within student users and therefore may make it a space that they are more likely to use. 
Figure 14. Affective Responses to the VUW Libraries

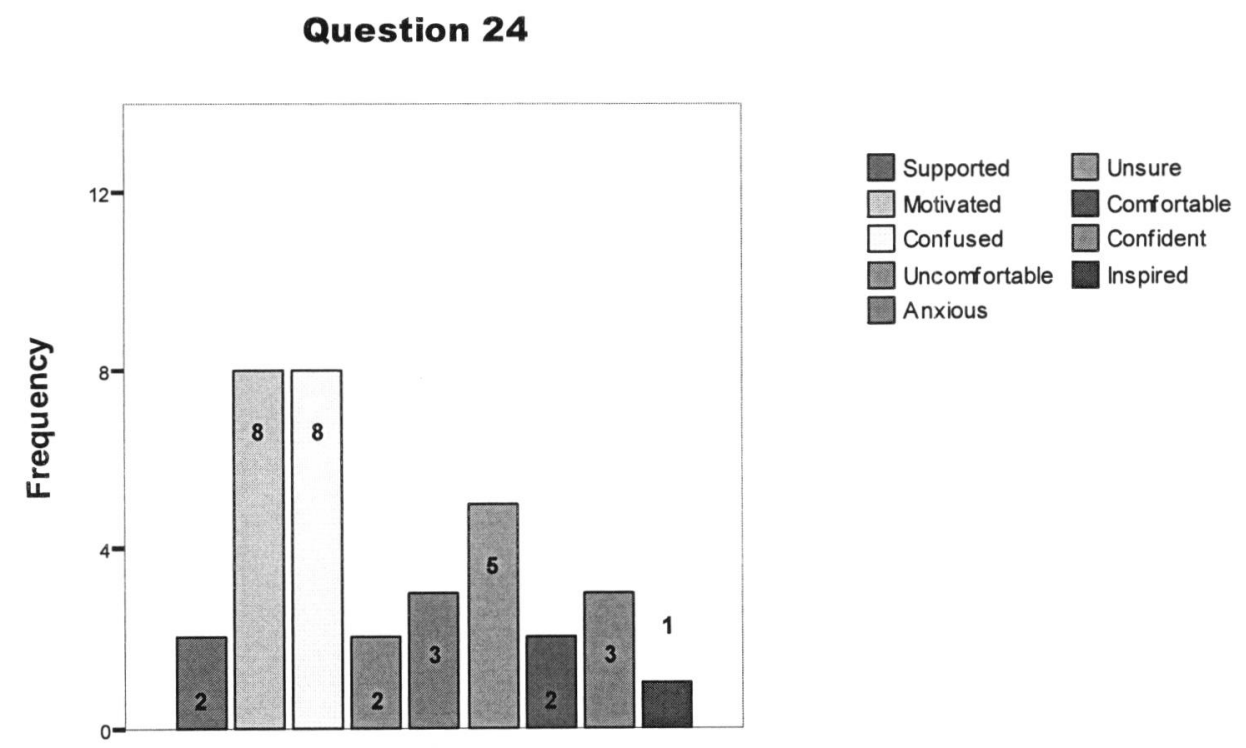

Feelings experienced by students when using the VUW Libraries

The next question asked students how they felt about using the VUW libraries. The response here was much broader than that for the Class Library (see Figure 14). The predominant feelings students experienced when using the VUW libraries were "motivated" (8), "confused" (8) and "unsure" (5). One student commented that they felt "frustrated" as the books they were looking for were not on the shelves.

There is more of a "spread" of feelings experienced while using the VUW Libraries in comparison to those experienced when using the IIML library. Students experienced comparatively more negative feelings ("confused," "unsure" and "anxious") and so library anxiety may certainly be an issue for some Creative Writing students that governs their use of the VUW Libraries. If it is a factor, it may modify the concept of library usage being solely based on how well a library meets an information need. 
Figure 15. Affective Responses to Public Libraries

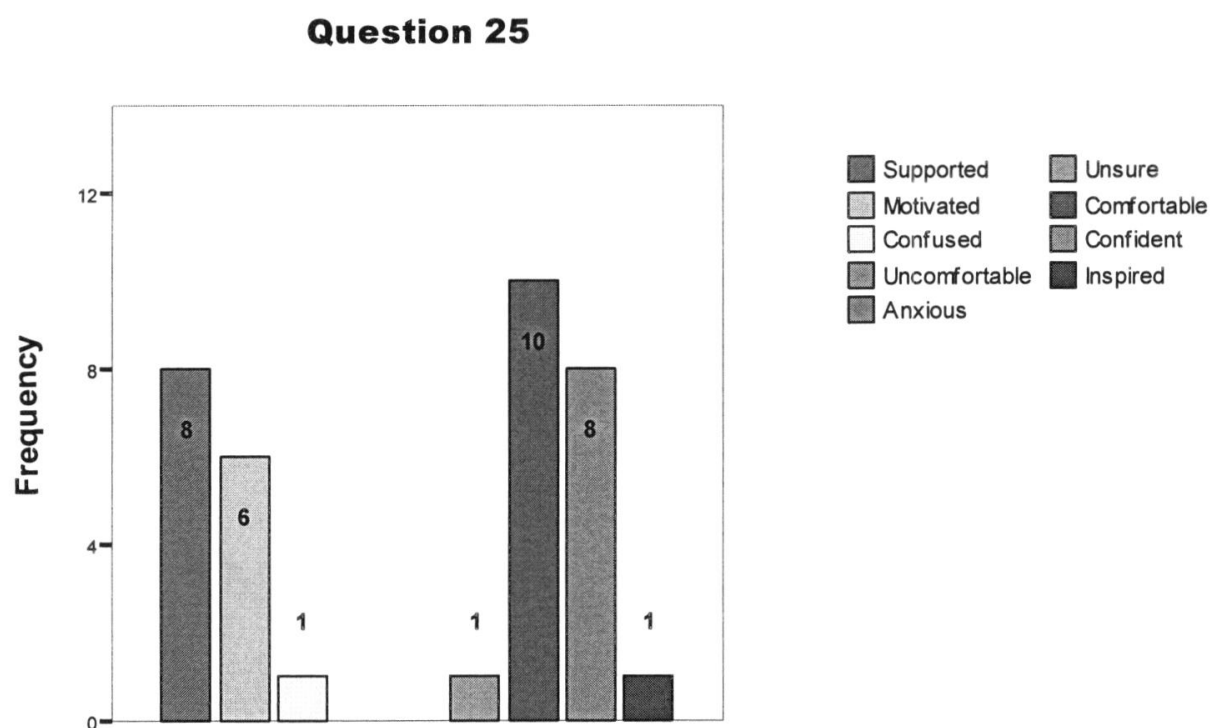

Feelings experienced by students when using the Public Libraries

When questioned about how students felt when they used the public libraries, students mostly felt:

- Comfortable (10);

- Supported (8);

- Confident (8); and

- Motivated (6).

Very few students included negative responses with regards to the public libraries and how it affected them: one "confused" response and one "unsure." This may be a reflection of students' familiarity with using public libraries prior to study in the MA (Creative Writing) programme, and that they therefore are comfortable and have a practiced confidence when using them. It could also be a reflection on the quality and service ethic of the public libraries that these students used.

When comparing students' affective responses to each of the three main libraries available to them while studying it is clear that they felt more positive when using the Class Library and public libraries than when they used the VUW libraries.

Of the three, the Institute's collection induced a feeling of inspiration much more strongly than either of the other two. This perhaps could be attributed to its proximity to the teaching space of the programme and the creative mindset that students engage in when they are learning, but further study would need to be undertaken to support this concept.

Question 26 asked students their opinion on whether the International Institute of Modern Letters Class Library should remain an autonomous and separate collection housed in the Institute or whether it would be better for it to be integrated into the VUW Central Library. All but one of those students who responded to the survey 
believed that the class library should remain separate and not integrated into the VUW Central Library.

Survey participants had varied reasons for this belief. The main reasons for retaining the Institute's Class Library as a separate collection were:

- The easy accessibility of the collection; and

- The comfortable and non-threatening space in which it is housed.

Another significant reason students felt it was important to maintain a separate library was due to the students' negative perception of the VUW Central Library, especially:

- The frequent lack of availability of collection material;

- The age of the majority of the literature in which students had an interest; and

- The VUW Central Library's lack of ease-of-use.

A typical example of this type of response is: "the VUW library is a nightmare - I found books that haven't been taken out since the 1970s! It's noisy \& it's difficult as a new user - to understand the bizarre layout. All those lovely IIML books would be lost to the black hole!"

There were other factors that governed students' opinions. Students also liked features of the Institute's Class Library, such as its being specifically for their use and thus of more relevance to their study; the availability of its resources; its ease-of-use; long issuing period; and its well organised resources. Participants fear that integration of the collection into the much larger VUW Central Library would lead to the loss of these appreciated features.

Only one student felt that integration should be considered, but only on the condition that it improve the availability of its resources: "... if the VUW Library cannot improve its level of books which are 'missing' for whatever reason (unshelved or lost in the library or stolen...) then the IIML should keep its collection separate." Another student suogested that hecause snace is an issue writh romarde to the clace lihrarv'c Iram

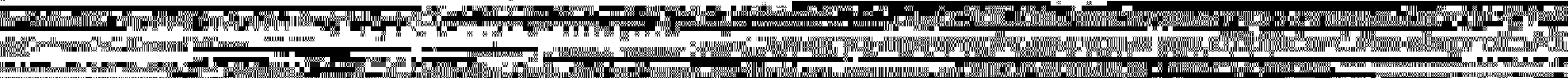

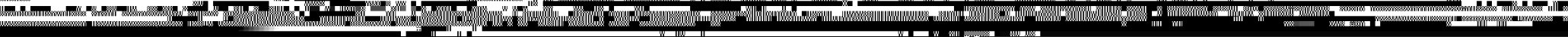

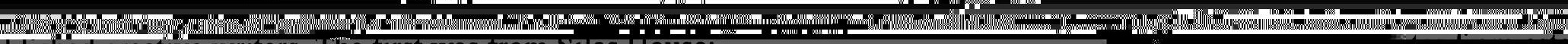

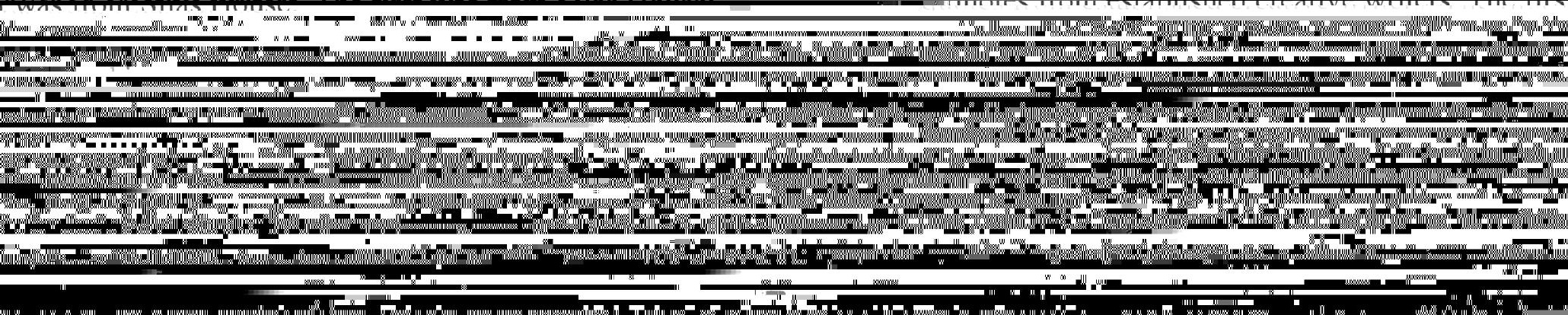


one student said that they got "...90\% of... [their]...inspiration from reading other writing."

It is also a necessary process in which every writer engages in when they reflect on their own work. One student said that reading great books can inspire people to become writers, and another felt that it was not only important to read great books but also to read "bad" books and learn which methods or techniques work and which do not.

This agrees significantly with accounts from many established writers who, time and again, cite the importance of reading in their writing lives (see Section 1.2.4).

Those that disagreed thought that reading was not the only way to become a great writer and that it could, in some ways, impinge negatively on the creative writing process by influencing the nascent writer too strongly and overshadowing their developing voice. One student noted that "...I think by reading too much it would be possible for me to even subconsciously emulate other writers."

The second quote that Creative Writing students were asked to comment on is from Mempo Giardinelli:

"I learned at... [a range of libraries]...that the best thing to do was read at random but, as someone breathes, incessantly and vitally."

Here the quote was employed to discover whether students thought libraries were of any importance in the creative writing process. There was a range of responses, with students responding to different aspects of the quote or to the quote as a whole. These aspects included:

- The importance of libraries in the creative writing process;

- Reading in the creative writing process;

- Reading at random - every "book" can offer a lesson;

- And reading, "...incessantly and vitally..." - does this interfere with the creative writing process?

The majority of students (13 of the 16 students that responded to this quote) agreed with one or more aspects of the quote, but there was no strong correlation of which aspects they agreed with. Some agreed with the importance of reading from a diverse range of material and persistently, but felt that libraries were not necessarily a part of this process. One respondent wrote: "I agree in the importance on the variety of resources, but there are other places to get books." Another student commented that "I don't know if random is a good idea - it's like deciding 'you'll open the Bible at random \& see what it tells me today'. What's wrong with selection?"

The importance of libraries in the creative writing process drew more positive responses than negative. The importance of reading, as highlighted in the previous quote (Silas House), was questioned as scriptwriters made more use of visual media, such as movies and so on, to provide them with the models of craft and for inspiration.

${ }^{52}$ Mempo Giardinelli, “The Library in the Life of a Writer," IFLA Journal 30, 4 (2004): 289. 
This ties into the idea of libraries being book repositories and print-bound (although today libraries, especially libraries that service the public and academic communities, provide a wide range of materials in many different media formats). The majority of the material available to students from the IIML collection is print-based, and so fits the traditional idea of libraries more than public and academic libraries.

The final question in the questionnaire asked students if they had any other comments relevant to this research study that they would like to make. The majority of comments students made related to growing and retaining the International Institute of Modern Letters Class Library and suggesting more ways in which to improve it: "A DVD collection should be part of the collection for the screenwriters. The screenwriting collection should be expanded." Other comments related to their perceptions of the VUW Central Library, many already articulated in the responses to question 26 (Section 3.1.4), or perceived inadequacies in the current collection of the Institute as explored in question 13 (See Section 3.1.2). Some students also remarked on how helpful they found the administrative staff of the Institute to be.

One student responded to this question with a general positive response to libraries overall: "libraries are one of the last purely generous and inclusive institutions left. The existence of libraries gives me hope for society." This response implies that libraries have a positive impact on society, but the reasons for this opinion are not given. This theme is explored further in the interview results given below.

\subsection{Interviews}

In addition to the questionnaire, several interviews were conducted as part of this sequential mixed methods research project. These interviews included:

- Focus group interviews with Creative Writing students from the 2005 class (section 3.2.1);

- Bill Manhire, Director of the International Institute of Modern Letters and a lecturer of the Master of Arts (Creative Writing) programme (section 3.2.2); and

- Mary Innes, Collection Development Librarian in the Victoria University of Wellington Central Library (section 3.2.3).

The focus group interviews were intended to investigate some of the themes touched upon in the questionnaire, such as the importance of reading and libraries in the creative writing process. Also, it was planned that students would explore the connections between libraries, creative writers and society. This was done to contextualise the study and its importance by assessing the importance of creative writing to society.

In interviewing Bill Manhire, the intention was to investigate his relationships with reading and libraries as an established writer, and ask what importance he placed on these in his teaching. He too was asked to explore the relationships of libraries, creative writers and society.

Mary Innes was interviewed to discover how the Central Library goes about meeting the information needs of Creative Writing students and what other relationships, if any, she has with the students and staff of the MA (Creative Writing) programme. 


\subsubsection{Student Focus Group Interviews}

Two interviews were conducted, as there was difficulty in organising enough participants for them. The first was conducted as a focus-group interview with two students. The second interview took place with only one student. The interview schedule may be found in Appendix C. As can be seen from the schedule, the interviews were structured to:

- Address the importance of creative writing to society;

- Assess the importance of libraries to the creative writing process;

- Further establish what relationships and connections lay between creative writers, libraries and society; and

- Canvass student responses to quotes from noted authors on these and other aspects of writing.

\subsubsection{The Importance of Creative Writing to Society}

Those students that participated in the focus-group interviews felt that creative writing was very important to society. One student felt that creative writing told the truths of society in such a way that more people had access to them than if they were discussed face-to-face. These truths could relate people to one another through the identification of shared experiences, and this meant that "...people aren't so isolated." ${ }^{, 53}$ This ability to relate is not necessarily a product of the content of the creative work, but may be invoked by the feelings experienced by readers in response to the work.

Creative writing provides entertainment and a way that people can be inspired. It can have an effect on "... peoples' outlook on life to read something uplifting... or it can condense something into something they can understand, something that is too big an emotion, that's too big a grief or fear or loss, and all those things can be put into a form that can give comfort or...understanding....,54

One student felt "...that a literature is one of the critical things in a culture;...I think... New Zealand writing is part of what makes New Zealand culture...,55

When asked if they could quantify the importance of creative writing to society, they felt that, for them, it was of great importance, but stressed that this was a subjective opinion on their part. One student felt that creative writing is part of the historical human document in that,

"... it has...plotted man's progress through the ages and I think it's that vital;... as much as anything it shows how we change, how we adapt, the psyche of human beings, how that has its fashions and its times and its trends..."

Not only this, it shows our social evolution from a variety of viewpoints looking both into the future and into the past and demonstrates that "... we strive to find ways of

\footnotetext{
${ }^{53}$ Interview with Focus Group, May, 2006.

${ }^{54}$ Interview with Focus Group, May, 2006.

${ }^{55}$ Interview with Focus Group, May, 2006.

${ }^{56}$ Interview with Focus Group, May, 2006.
} 
communicating and we do it by writing and reading what other people have written." 57

Creative writing humanises history as written by historians, which has, in and of itself, a measure of creativity in it also.

The next question asked participants "how much of your work do you feel is part of the 'dialogue' of society or reflects themes that are topical?" For the most part, the student interviewees found that their work was more reflective than explicitly participating in political or societal dialogue. The three participants were all poets and felt that their work was more evocative and that the focus of their work was tighter in that they tended to reflect on ".... little thing and putting it somewhere that speaks... about something bigger." $" 58$ This reactive behaviour may be more symptomatic of the style of writing in which they are engaged; perhaps novelists might participate in societal dialogue in their work more explicitly.

One student noted that because her work is "...of its time, so consciously or not there will be things in it that are kind of triggered by and responding to things that are happening in the world..." 59

Regardless, this reflective or reactive practice is, in an ephemeral sense, engaging in societal dialogue, in that the readers engage with the work in a way that connects with their previous experiences in the world.

The themes which the participants explore in their work include how people relate to one another, especially in close relationships or with historical perspectives.

How the students became writers was much discussed. The participants felt that they didn't "become" writers so much as answer a compulsion within themselves to express what they were thinking and feeling through writing. One student felt that writing "... seemed to be the only expression that truly cleared the [mental] decks... and was satisfying in that way of naming some sort of emotional thing that you'd seen or observed or something and putting it in a way that just felt really satisfying and complete." 60 This student felt that they were responding to a psychological need to express themselves "... after being silent for such a long time.",61

Another student noted that publishing took that expression further by exposing oneself, whether the work was self-referential or not, to the world. Writers reveal a lot about their thought processes when writing and being published exposes society to those processes. They felt that in expressing themselves they added a voice to an existing understanding of what people experience in different ways.

\footnotetext{
${ }^{57}$ Interview with Focus Group, May, 2006.

${ }^{58}$ Interview with Focus Group, May, 2006.

${ }^{59}$ Interview with Focus Group, May, 2006.

${ }^{60}$ Interview with Focus Group, May, 2006.

${ }^{61}$ Interview with Focus Group, May, 2006.
} 
This student felt that, for them, “...if only I could...get out what I actually want to write! I mean that's the challenge of my life really." 62

In writing, students further hone their skills; “...it is a skill to...put words in relation to each other in just the right way for the piece that you're writing and I think the more you practice like anything, the more you're reading, the more you write, you know...you get a flavour of your own style and that becomes sort of your voice." ${ }^{, 63}$

By publishing, writers make this voice known to the world and student writers had various opinions on aspects of being published. One aspect, the feedback from readers, is something which student writers are understandably apprehensive of. The fact that you cannot count on a positive response is "...one of the really scary parts... and I think it's almost like, you know, Janet Frame who said...posthumous publication was the only really safe, seemly, or most appropriate way to be published, if you're dead, and I can totally understand." 64 This fear of a negative response by readers highlights to student writers the importance of developing an awareness of their audience.

While enrolled in the Creative Writing programme, the audience they wrote for was principally themselves, their lecturers and classmates, which provided a supportive atmosphere where they could play around with their expression and hone their skills without subjecting themselves to the possibly negative response of a wider audience. This reflects the idea that society does have an effect on writers and to a lesser extent on their writing.

\subsubsection{The Importance of Libraries to Creative Writing}

To explore what importance libraries had to the creative writing process, students were asked how reading inspired the writing urge in them and thus how libraries could indirectly inspire this urge.

Interview participants felt that their reading did inspire the creative writing urge in them. One student said, "I can think of some poems that I've written that have been direct response to other poems that I've read almost like a conversation..." sometimes they can be inspired by a phrase or another writer's use of form.

The way in which this inspiration takes place provokes students to put forward a number of metaphors:

- Reading inspirational work starts the clockwork machinery of creation, with all of its cogs and chains, ticking over and this drives students to write;

- It flips a switch in the writer's mind that causes them to move into a more creative mental space, outside of the everyday thoughts nearly everyone thinks;

\footnotetext{
${ }^{62}$ Interview with Focus Group, May, 2006.

${ }^{63}$ Interview with Focus Group, May, 2006.

${ }^{64}$ Interview with Focus Group, May, 2006.

${ }^{65}$ Interview with Focus Group, May, 2006.
} 
- Reading well-expressed creative writing can spark the creative process so that one theme can inspire a reader to think of and then write about something entirely different.

One student reads poets who have a particular lyric quality in their work as that is something that they wish to include in their work. It is not necessarily a straight copying of the feel of those poets" work, but "...to get into that mindset of thinking."

Reading others' work can be, like music, evocative and provide an escape from the mundane to the creative mind-space.

Some established creative writers have said that they have been inspired directly by their experience of libraries to become writers, although this was not the only factor that inspired their choice of profession. The student participants of the focus group interviews were asked whether they too were inspired by their early experience with libraries to "become" writers.

The three students answered "no," but one student did note that the libraries of their childhood did have a direct effect on their choice of reading which now has an effect on their writing. Two students noted that their experiences of creative writing at primary school did have an inspirational effect on them, however: "...the way you were taught writing was a quite a significant part of the education that I had...I can remember having one of the best experiences at my primary school was when you had to write and click[ing] into writing creatively."

One student said,

"listen, I just really like the strange feeling of actually creating, getting the effect with words which seem to me to sort of be describing, or getting, or sort of capturing autumn, aspects of autumn; it's like recreating it, like being a god, having that ability to recreate life just with words and sort of see it..."

and they were aware of this feeling that it was always possible to creatively write if they chose to do it.

This question also provoked one student to describe their hatred of university libraries and the anxiety and panic attacks they felt when they used them. When arriving at Victoria University to study in 2005, this student required someone to take her around the VUW Central Library because of her phobia. This feeling of anxiousness was derived partly from the atmosphere that the student experienced while within university libraries: feelings of competition where students hide or steal books which made it difficult for them to find books that the library catalogue said was on the shelves; the fustiness in the library; and the huge amount of "...old, old books." ${ }^{69}$ This student does not experience this anxiety in other libraries like the Institute's Class Library or public libraries. The shortage of contemporary fiction identified in the questionnaire is perhaps what causes Creative Writing students to be in among all the older books.

\footnotetext{
${ }^{66}$ Interview with Focus Group, May, 2006.

${ }^{67}$ Interview with Focus Group, May, 2006.

${ }^{68}$ Interview with Focus Group, May, 2006.

${ }^{69}$ Interview with Focus Group, May, 2006.
} 


\subsubsection{Establishing Relationships between Creative Writers, Libraries and Society}

This section of the interviews took up the most time and explored a number of themes. Participants were asked:

- How important is publishing to the writing self?

- How important is the physical published object?

- What relationships did they have with libraries?

- Were there any libraries promoting their work, or that had made attempts to promote their work in the past?

- What relationships or contacts did they feel existed between creative writers, libraries, and society (see Figure 16 below).

The importance of publishing to the writing self "...probably varies a lot from writer to writer..."70; for some writers it would be a critical step towards validation of themselves as writers, while others would continue to write without ever publishing. Some see it as important, as you "...can reach a larger audience by being published [and] you want your work to be recognised..."71 This recognition is not a necessity though as publishing in the area of literature is highly governed by fashions and trends and so not everyone's work would be appreciated and published at any given time. One student felt that to be published helped maintain the motivation to write as well as provide some "moral" feedback in such a way that writers improve their work after being published. Because writers may expose their thought processes in their work, feedback on their work "...makes you really sort out your way of thinking and your way of relating to the world..."72 One student felt, that in being published and receiving this "moral" feedback, that they became a more well-rounded and better person.

Society therefore has a profound effect on writers through its response to their publications.

Publishing is not without its risks however. The type of feedback you receive, both positive and negative, can have corresponding positive and negative influences on the writer, and as a writer, all you can hope for is that you will have sympathetic readers.

The importance of the physical published object prompted the following response: "There is something very, very viscerally nice about holding...something that you're in..." 73 As a reader, this student felt that the physical nature of a book was quite important in terms of the weight of it, the type used for the printing, the size of the margins and so on, as it "is really a part of the experience of reading..." Internet exists now, this student did not feel that it had yet realised a more beautiful and easier to use environment for reading online, and thus the physical published object would maintain its importance.

\footnotetext{
${ }^{70}$ Interview with Focus Group, May, 2006.

${ }^{71}$ Interview with Focus Group, May, 2006.

${ }^{72}$ Interview with Focus Group, May, 2006.

${ }^{73}$ Interview with Focus Group, May, 2006.

${ }^{74}$ Interview with Focus Group, May, 2006.
} 
The relationships that these students had with libraries were predominantly making use of the libraries for their own recreational and research reading. They did not feel that many libraries made much of an effort to promote their work, although the National Library did host an exhibition at which a student of the 2005 class was invited to read their work.

Indirect promotion occurred through libraries choosing to stock books and anthologies published by past and present students of the MA (Creative Writing) programme. The Institute's library stocks everything published by its students and from noted New Zealand publishers and is seen as an interested library. The central public library is seen as "... such a happening thing I don't think they feel they need to attract [more readers].",75

They felt that much more could be done by libraries to promote their work directly to potential readers, such as:

- Staging or having writers do readings within the libraries; or

- Providing a separate display stand for new New Zealand creative writing publications.

Readings by creative writers occur frequently in Wellington but principally occur in bookshops where established writers are promoting their new work.

This lack of promotion is attributed to two factors by the focus group participants: lack of adequate funding by publishers, who are themselves under-resourced; and the perceived lukewarm interest of librarians in their work.

Figure 16. What Relationships Exist Between Creative Writers, Libraries and Society?

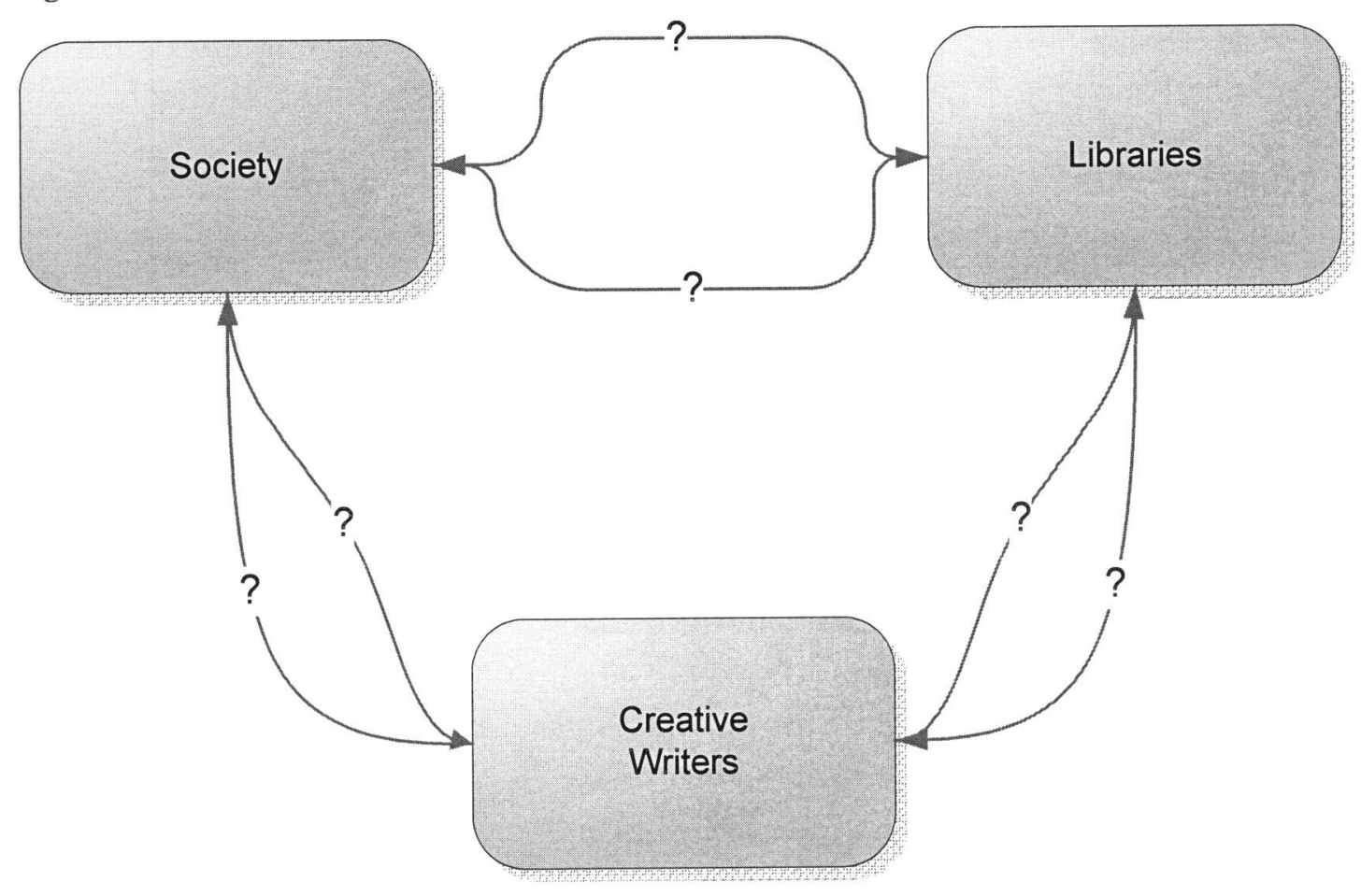

${ }^{75}$ Interview with Focus Group, May, 2006. 
Students were referred to the figure above (Figure 16) and asked to further establish what relationships and connections lay between creative writers, libraries and society.

There was a variety of responses, both specific and tangential to the possible relationships derived from the diagram. They included:

- The threats to existing libraries from funding agencies that may not see their importance to society;

- The separation of fiction from literature in the non-fiction section of public libraries;

- Libraries stocking the product of creative writers;

- Creative writers acting as advocates for libraries;

- Libraries being historical repositories for society;

- De-accession practices of libraries and the effect this has on their readership;

- The operational processes of university libraries that mean it takes some time from publication before a book may be available for issuing;

- The unfriendliness that some creative writers experience while using libraries;

- Promotion of creative writers' works by libraries, but on the library's terms;

- The importance of libraries to societal mental wellbeing;

- The accessibility and "free" nature of libraries;

- Libraries acting as community spaces;

- Creative writers' need for libraries as places of research; and

- Libraries providing readers with a wide range of material to read.

These themes can be grouped into what elements of creative writers, libraries and society they cover. It must be noted that the diagram above is not representative of how the three elements exist, as creative writers and libraries exist within society but were represented in that way to aid students in identifying links between them.

The first sets of connections are those between creative writers and libraries. Libraries have a financial relationship with creative writers as they stock the product of the creative writing process and pay for this privilege. For those writers in New Zealand who are little-known at this point, funds from the sale of their publications to libraries may be a significant part of the income they receive from those works. When the library provides access to their work, they disseminate it to a wider audience than would necessarily be managed by sales to the public alone. This public awareness may increase sales in the long term.

Another connection is the promotion of creative writers' works by libraries. One student mentioned that the National Library does promotional exhibitions, but felt that these promotions were on their terms (the library's) with little input from writers.

An important relationship that creative writers have with libraries is their use of libraries for research. A focus group participant said that “...libraries can make...it user-friendly for creative writers by having a good selection... New Zealand literature and stuff I think libraries should keep current books, of new things that are being published... ${ }^{976}$ The participants were of the opinion that most creative writers make use of libraries for creative purposes.

\footnotetext{
${ }^{76}$ Interview with Focus Group, May, 2006.
} 
Despite this need, creative writers can be put off using a library when they feel unwelcome or if they find the atmosphere unfriendly. A participant recounted her experiences with using the National Library: “...they've got their system and they know it really well and...it's like, when you walk in you go, 'how does this work?' You have to actually, you feel like a real klutz because they seem to all know what they're doing and no-one takes any notice of you..."77 This also relates to the student who recounted her feelings of anxiety when using university libraries.

Another student noted that they felt the separation of fiction from literature in the nonfiction section of public libraries meant that "...fiction was somehow frivolous and not improving and you know, not like worthy cooking books and carpentry..."78 They felt that this practice should be abandoned and general fiction should be included with the classified (800s in the $\mathrm{DDC}^{*}$ ) literature.

A further identified issue resulting from the relationship of libraries to creative writers was the result of other library operational processes. A participant said that "...it takes forever to find a book in the library that's been published, the year before even, it seems to take a long time... but it should have everything that is coming out I reckon for creative writers." 79

The second sets of connections are those between libraries and society. The accessibility of libraries and their "free" nature was one connection that was made. One student said that "I can never believe it actually, I often walk into the library and go 'I can't believe this is free' this is a free activity for the afternoon I can come in here and do this..." 80

Most libraries offer such a wide range of material to its users that it can take an afternoon to browse leisurely through them: “...it's amazing when you walk through that library [Wellington Central Public Library] and they have...those displays of new books, and books that the librarians have decided to put up there and you think, 'God, so many interesting books' and I would love to grab just heaps of those I'll grab that one and that one and ooooh! Ah! Yes! And then you think, well, I suppose I could take that one because you realise that there is just so much that you could read." 81

The accessibility of the collections, not having to pay to take books out (unless they are new bestsellers and so on), and having such a wide range of reading and other material to browse make libraries, especially public libraries, a popular recreation area for those populations that they service.

Focus group participants commented that this highlighted the importance of libraries to the mental health of society: "I think libraries are...pivotal to society; I think that they're pivotal, that should be free. I think it is just such a gift to society that... the city

\footnotetext{
${ }^{77}$ Interview with Focus Group, May, 2006.

${ }^{78}$ Interview with Focus Group, May, 2006.

* Dewey Decimal Classification

${ }^{79}$ Interview with Focus Group, May, 2006.

${ }^{80}$ Interview with Focus Group, May, 2006.

${ }^{81}$ Interview with Focus Group, May, 2006.
} 
council or the government... will fund a public library...I mean, people know of the importance of that obviously, or they wouldn't do it otherwise, but they know that it has a huge role for many people in keeping...[good]...mental health..."

This may be due, in part, to the provision by libraries of what one student called "nonreal experience." Library users may expand their knowledge through a mode other than that of direct experience. Of course, this can be true for any other provider of information, but libraries provide a broad range of information for users to incorporate into their knowledge base. An interview participant recollected that they felt, when they were younger, that they derived a lot of knowledge from their reading, but when they grew older and "...started experiencing real life that it was a different thing, a different type of experience and it modified... [their]...ideas and...

[their]...thinking of life..." 83 and now they achieve a balance between those two ways of experiencing, gaining information and increasing their knowledge.

Libraries also act as community spaces and contribute to society in that way. With regards to the Wellington Central Public Library, a Creative Writing student said: "It's great... 'cause actually everyone does use the library you know...guys with dreads and you know, it's fantastic. You know some of the...old guys...

[who]...don't have much to do and they just spend the whole day in the library just sort of living there really, it's really fantastic and they're at home there." ${ }^{\prime \prime 4}$

Another link between society and libraries is that often libraries, along with archives, act as historical repositories for society. Libraries, unlike the majority of bookshops, can give readers access to older, frequently out-of-print, material. This is very important for those with an interest in not only history but a host of other subject areas, such as geography, art and sociology.

Despite what libraries offer to society, funding agencies, such as city councils, do not always feel that they are of particular importance. So another connection between libraries and society is financial. One student recounted that they were in the past involved with a support group for a public library that was under threat from closure and was already under-resourced to meet the needs of the community adequately. This was due, they felt, to the council placing more emphasis on funding sporting events and venues than on the library.

An operational process of libraries that impinges on their relationship with society and the communities within it is de-accession. The process of "weeding" the collection and disposing of material that is not frequently used or is out-of-date is a common practice in most libraries. One student said that "I would probably use libraries for both literature and other resources that have got...a longer term...life and so I suppose I get anxious when libraries want to de-accession things, the sorts of things that I'm interested in I guess I like to imagine that they will always be there no matter...[when I] ...go.".85

\footnotetext{
${ }^{82}$ Interview with Focus Group, May, 2006.

${ }^{83}$ Interview with Focus Group, May, 2006.

${ }^{84}$ Interview with Focus Group, May, 2006.

${ }^{85}$ Interview with Focus Group, May, 2006.
} 
Although the relationships between creative writers and society, the third set of connections from the diagram (see Figure 16), were not explicitly stated by participants, as members of society, creative writers relationships are shaped also by those between libraries and society.

How strongly these relationships and connections correlate is disputable give the smallness of the sample group, but some of these themes are echoes from those reported in the questionnaire (see Section 3.1.4) and are further touched on by Bill Manhire in the interview below (see Section 3.2.2.2). It is obvious, however, that libraries have a profound effect on creative writers and have well-established connections with the communities they serve.

\subsubsection{Quotes on Aspects of Creative Writing}

The following quotes were shown to the focus group participants to garner responses about various aspects of creative writing. They were asked whether they agreed or disagreed with a quote and if they felt that there were themes that weren't touched upon that they felt were important.

The quotes were taken from articles that were included in the literature review (see Section 1.2) as well as from an online quote website. ${ }^{86}$

\section{"...every writer that speaks about reading begins by evoking the library that moulded him." - Mempo Giardinelli}

Two of the three student participants agreed with this quote. As a writer, one student thought "... a lot of the valuable stuff that comes...to a writer, has often come from libraries because it's free...The actual books you can buy and get... to own is pretty miniscule, compared to what you can get access to in the library. I think that a library would have been usually in most...cases... would have been just so much the significant experience. ${ }^{87}$ The other student who agreed felt that not only physical libraries have an impact, but also "... a mental spiritual library..." "88 that "holds" all the works that have had a significant impact on the writer, the works they have read during their life.

The third student did not agree as they did not feel they had been moulded as a writer by a library, as many times their experience of libraries was one of frustration and not being able to find what they wanted.

The importance of libraries to the creative writer, as stated in the quote, seems to gain a ready response from some writers, but not all.

"Libraries gave creative writers the opportunity to read the work of a wide variety of authors. This provided them with inspiration and ideas for their work." - Cameron Barrie

\footnotetext{
${ }^{86} \mathrm{http}: / /$ www.memorablequotations.com/

87 Interview with Focus Group, May, 2006.

${ }^{88}$ Interview with Focus Group, May, 2006.
} 
One student responded to this quote felt that it was prosaic and gave the impression that libraries are over. Furthermore, "it's actually very narrow in what it's saying about the role of libraries..."89 This quote is from an Australian librarian who was talking about the threat to the state library to which he was attached and this perhaps prompted the feeling that "libraries are dying out" to the student.

The quote was included as it reiterates the idea that libraries are of great importance to creative writers. The somewhat ambivalent response does not match those responses that students have made to the other quote on this theme or in the qualitative questions (especially question 28) of the questionnaire.

"From every book invisible threads reach out to other books; and as the mind comes to use and control those threads the whole panorama of the world's life, past and present, becomes constantly more varied and interesting, while at the same time the mind's own powers of reflection and judgment are exercised and strengthened."

- Helen E. Haines

All three participants agreed with Helen E. Haines point on the connections between books by invisible threads. One participant said that "...there are interesting connections that you don't necessarily see..." many interpretations of universal themes in the world, everyone's experience is unique and you can't help but be influenced in what you write, by what you have read and enjoyed. There are many crossovers." 91

The connections between books, those published and those being written, highlights the importance of reading to the creative writing process. It also emphasises the importance of libraries, as providers of reading material, to the process.

"Read, read, read. Read everything - trash, classics, good and bad, and see how they do it. Just like a carpenter who works as an apprentice and studies the master. Read! You'll absorb it. Then write. If it's good, you'll find out. If it's not, throw it out of the window." - William Faulkner

Students agreed with the imperative to read in the above quote from William Faulkner but had differing opinions with the rest. One student commented that what you consider "good" and "bad" is subject to change, while another felt that you read constantly as the world is full of text, in magazines and on notice-boards, but in them this deluge of "mundane" reading incited a craving to read good books.

These responses to the Faulkner quote emphasise the importance of reading to the creative writer yet again. As providers of reading material, libraries can be seen to have indirect importance, too.

"The final lesson a writer learns is that everything can nourish the writer. The dictionary, a new word, a voyage, an encounter, a talk on the street, a book, a phrase learned." - Anaiis Nin

\footnotetext{
${ }^{89}$ Interview with Focus Group, May, 2006.

${ }^{90}$ Interview with Focus Group, May, 2006.

${ }^{91}$ Interview with Focus Group, May, 2006.
} 
Each of the interviewees agreed strongly with what Anaïs Nin has to say in the above quote. One student agreed that anything can nourish the writer, "...but the libraries, but other people's writings are really important in that too" $" 92$ and that they thought "...that good reading and better writing tend to go together."

Again, the importance of reading to creative writing was touched upon and was further reinforced. There is some debate here as to whether random or selective reading is best. When touched on in the questionnaire, students seemed to feel that same ambivalence as to which is more useful to the creative writer.

Another response was prompted by how the quote itself was expressed: “...it's a strange thing about writing ... that if you bother to do it, you often find yourself saying something quite original that you didn't [think you would], and if you tried to, you couldn't, but if you just write what you think and just keep writing there would be a lot of things that have never been said but could do with being said." 94 This ties in better perhaps with the responses to Le Guin's "translation" quote (given below), as it gives some insight into the creative writing process.

"Translation is entirely mysterious. Increasingly I have felt that the art of writing is itself translating, or more like translating than it is like anything else. What is the other text, the original? I have no answer. I suppose it is the source, the deep sea where ideas swim, and one catches them in nets of words and swings them shining into the boat ... where in this metaphor they die and get canned and eaten in sandwiches." - Ursula K. Le Guin

Here the respondents felt that Ursula K. Le Guin made a good point. Not all writing feels as if it was produced in an act of translation, "....sometimes writing comes like a song or like music, you know and it sort of like writes itself quite directly..." ${ }^{\prime 95}$ but it is a common feeling the respondents felt: "I remember saying this about one of my very early poems...they asked me what it was like writing it and how it came about, and all the things I said that it was like, are translations and...I had visual images in my head... and it was like...translating those, that form into a like form." ${ }^{.96}$ Sometimes it's not necessarily a translation from one medium to another, such as a visual medium to a text-based medium, but a particular care taken in the placing of words in relation to each other. The translation of the unconscious into the conscious was a theme which was remarked upon: “... what you've got is what you think is the material, and then what kind of alchemical things... happen that you don't understand and somehow you've got this thing that's got this other life you know a parallel...",97

Including this quote in the interviews was intended to help develop a better understanding of the creative writing process. A more cogent understanding of the process would allow for a more comprehensive awareness of what drives creative writers' information needs and the ways in which these are best met. Also, an

\footnotetext{
${ }^{92}$ Interview with Focus Group, May, 2006.

${ }^{93}$ Interview with Focus Group, May, 2006.

${ }^{94}$ Interview with Focus Group, May, 2006.

${ }^{95}$ Interview with Focus Group, May, 2006.

${ }^{96}$ Interview with Focus Group, May, 2006.

${ }^{97}$ Interview with Focus Group, May, 2006.
} 
improved appreciation of the creative writing process might help develop the understanding of their relationships with libraries and society further.

\section{"The unread story is not a story; it is little black marks on wood pulp. The} reader, reading it, makes it live: a live thing, a story." - Ursula K. Le Guin

For the most part, the three students agreed with Ursula K. Le Guin's idea that a story is a communication between a writer and their reader and it needs the reader for it to be transmitted. "As soon as it... [the story, is]...put down it's nothing but a construction, a physical construction, that means absolutely...nothing, until someone reads it." $" 98$ Part of the life of a story happens with the reader/audience. Another student suggested that the unread story was not an inert, dead thing but, "...it's like potential energy and kinetic energy maybe,...that the story has still got its own energy..." "99; it's just dormant.

This quote was included in the interview to further explore the importance of reader awareness to the existence of a creative work. It again shows that creative writers are impacted by society and this has an effect on their writing.

One respondent thought that one major theme not touched upon by the quotes given above was that "...to be a writer you must write, it is not enough to observe and read and take notes unless they go to form writing. Many people read for pleasure, and use libraries to that end, but I think for a writer it is work, it is a job, and the library is where, by reading, you research. Reading becomes a different pleasure when you are trying to use words yourself to be creative." 100 There is further reinforcement here for the theme that libraries are important to the creative writer.

\subsubsection{Interview with Bill Manhire, Director of the International Institute of Modern Letters}

An interview was conducted with Bill Manhire. The interview (see Appendix D) was intended to discover what attitudes he held with regards to reading and libraries as both a writer and as a teacher.

\subsubsection{Perspectives as a Writer}

When asked what he himself took from writing, Manhire replied that when "I... talk about the reading that matters most to me then I just like being completely caught up in the world of whatever the book is, as if you've crossed a border into someone else's imagination or some other place or some other country or some other time...",101

The majority of his reading is generated from his work, where the reading he does is by the aspiring writers in his teaching courses.

\footnotetext{
${ }^{98}$ Interview with Focus Group, May, 2006.

${ }^{99}$ Interview with Focus Group, May, 2006.

${ }^{100}$ Interview with Focus Group, May, 2006.

${ }^{101}$ Bill Manhire, Interview by author, Tape recording. Wellington, New Zealand, 5 May 2006.
} 
The n
work. 
use libraries for." $" 110$ So the inspiration factor is the most important contribution that libraries make to his creative writing, and this compares well with the findings in the questionnaire (question 27 and 28) and in the focus-group interviews, where students noted that reading made a significant contribution to their writing process and that libraries offered a wider range of material to inspire them than they were able to buy for themselves.

Furthermore, Bill Manhire noted that,

"...what I love about libraries in general is the fact that you can still bump into things. Most New Zealand libraries are still sort of open shelf sort of access you can wander around and bump into stuff you didn't know existed. I suppose it's like the internet made physical..."

\subsubsection{Perspectives as a Teacher}

The second part of the interview investigated how Manhire, as a teacher, promoted reading and libraries to his students. As a teacher, he puts quite a lot of emphasis on libraries as providers of resources in the sense that he understands that the majority of students do not have sufficient funds to buy all the books they need to read for the programme. The emphasis on reading in the course is so strong that it is assessed: students "...come to a workshop where they talk about the remarkable books... [they have read]... and they have to keep a reading journal of the stuff they've been reading during the year." 112 This is to ensure that students read beyond their own writing and that they come to further develop their own individual voice.

Manhire says that he does not place a great deal of emphasis on library staff providing expert assistance to students in locating research material or rare resources. He himself makes use of the reference staff at Victoria University's Central Library, but on the rare occasions that he suggests libraries to students as places where they can get help with research, it is often the Alexander Turnbull Library ${ }^{113}$ that he recommends.

He feels that it is more important for students to read "imaginative work that excites them before they get too caught up in research." 114 Mr. Manhire said that often students whose project is a novel get caught up in research as a displacement activity.

As providers of creative writing space, again Mr. Manhire puts little emphasis on libraries, although he does think that some students do like to go and sit in libraries, the Institute's library as well as VUW Central Library, and write. He finds that because the majority of libraries are "...nice, warm, brightly lit places..."115 there can be a lot of competition for the space they provide. He says that within some libraries, “...you join a kind of larger energy that's focused on thinking, and writing, reading

\footnotetext{
${ }^{110}$ Manhire, Interview by author, 5 May 2006.

${ }^{111}$ Manhire, Interview by author, 5 May 2006.

${ }^{112}$ Manhire, Interview by author, 5 May 2006.

${ }^{113} \mathrm{http}$ ://www.natlib.govt.nz/en/using/8atl.html

114 Manhire, Interview by author, 5 May 2006.

${ }^{115}$ Manhire, Interview by author, 5 May 2006.
} 
and so on"116 and this can be extremely useful for the creative writer. He himself is aware of at least one novelist that he has met who does all his writing in libraries. In general, however, he believes that most writers have to be alone, in a quiet place, to write. This matches with his own practice when creatively writing and the majority of student writers who responded to the questionnaire (question 2).

On the whole, he doesn't recommend many libraries to his students. The teaching staff has not recommended the VUW Central Library in the past to students for two reasons. The first is that their collection of contemporary fiction and poetry is lacking: "it's not even full of holes, it's mostly a hole with a few titles..." ${ }^{117}$ He is aware that in the past year the collection development staff at VUW Central Library have been working on addressing this deficit in their collection and that the problem was more due to lack of funding than any practice on the part of library staff. This issue has led teaching staff at the International Institute of Modern Letters to recommend that students look online or in the public libraries for recent poetry or fiction.

The second reason for not recommending students to use the Victoria University Central Library is the noise. Manhire says that he finds it's the worst library in his experience for noise, and feels this is due to students using it as a social space rather than a study space.

The teaching staff do recommend the Institute's Class Library to students, "... because, in fact, we've made a point of putting in a lot of books in there that we would like our students to read." 118 Manhire is aware that it is limited, however, because it has a very small budget that usually covers only journal subscriptions, and the bulk of the monograph collection is made up of donations from publishers such as Penguin and the Victoria University Press.

In preference to libraries, Manhire recommends bookshops to Creative Writing students. In this way they can build their own personal libraries, which is a common theme in "...the community of those who write and publish books." ${ }^{.19}$ By building their personal collections, students have books that can inspire and guide them within easy access when they are creatively writing at home.

Also, the Institute's teaching staff occasionally recommended students look for resources on the Internet.

As far as self-publication on the Internet is concerned, he does not think that it is a viable option for students. This is principally due to the interfaces with which readers are confronted when using computer-based visual media. He says that “...I don't think anyone else thinks that a screen is a better piece of information architecture than a book with pages." 120

The diagram that was shown to the focus group interview participants (Figure 16) was also shown to Bill Manhire, and he was asked what connections and relationships he

\footnotetext{
${ }^{116}$ Manhire, Interview by author, 5 May 2006.

${ }^{117}$ Manhire, Interview by author, 5 May 2006.

${ }^{118}$ Manhire, Interview by author, 5 May 2006.

${ }^{119}$ Manhire, Interview by author, 5 May 2006.

${ }^{120}$ Manhire, Interview by author, 5 May 2006.
} 
felt existed between the three elements of society, libraries and creative writers. He felt that, overall, the connections between the three resulted from a very slow process: "...just think of creative writers as the generating group as clearly they are...eventually what they do ends up there in the library, and eventually it ends up there in society. But it might take 50 years or a 100 years before...that's actually happened." 121

One example he cited were the confessional poets of the 1950s and ' 60 s, such as Sylvia Plath and Robert Lowell. Their works, which dealt with themes which were considered taboo at that time, were being published and disseminated by bookshops and libraries and eventually that freedom to express feelings regarding issues such as mental health found its way into society, and now "...there's not very much taboo stuff left." 122 In this way creative writing can shape society and this highlights its importance to society as a whole.

This connection between creative writers and readers is not one-way. The influence of the audience is a critical factor that can guide the creative writer in their writing process. He says that "... you are writing for readers, so that you read in order to be a writer, but you write in order to be read. And a lot of people just write in order to write and that's fine. But if you are serious about being a writer, then you write to be read." 123 This two-way connection allows for a societal dialogue to be established.

If writers remain unpublished and "...if they haven't imagined a reader then they might be writing very badly." ${ }^{124}$ Manhire was interested in how large the spaces between the three elements might be. Creative writers and libraries exist within society, but he felt that there was a

"...great danger for writers I think, and you can see it in some writers who believe themselves to be very much wiser than everyone else, is that the writer can become so remote from ordinary society, and normal social interactions, that they get everything completely wrong. How can you write a novel if you are standing on the fringe of society and sort of shaking your fists at the way people behave?...We...misrepresent just even the surfaces of what's there. So you don't want the spaces between society and the creative writer in any way too big..." 125

He did not make any comments on what connections he felt lay between libraries and creative writers or society but, in some part, the connections between creative writers and libraries were already addressed in earlier responses in the interview.

\subsubsection{Interview with Mary Innes, VUW Collection Development Librarian}

An interview was conducted with the Collection Development Librarian of the Victoria University of Wellington Central Library on the $12^{\text {th }}$ May 2006 (see Appendix $\mathrm{E}$ for the interview schedule). It was intended to discover how the

\footnotetext{
${ }^{121}$ Manhire, Interview by author, 5 May 2006.

122 Manhire, Interview by author, 5 May 2006.

${ }^{123}$ Manhire, Interview by author, 5 May 2006.

${ }^{124}$ Manhire, Interview by author, 5 May 2006.

${ }^{125}$ Manhire, Interview by author, 5 May 2006.
} 
collection development team went about identifying the information needs of the Creative Writing students, how they met these identified needs and what relationships the library has with them.

The current methods by which the VUW collection development team identifies the information needs of students, including the students of the International Institute of Modern Letters, is by information provided about the courses in the prospectuses and online as well as feedback provided by the lecturers, liaison librarians that work in each subject area (the Master of Arts [Creative Writing] falls under the supervision of the Liaison Librarian for the English Department) and from the students themselves.

The principal way in which these identified needs are met is by taking all the feedback that they receive and allowing it to inform collection development. However, Mary Innes said that "...in practice what happens here is we buy pretty much anything that is requested by lecturers." practice are budgetary and relate principally to journals and very expensive items.

The current preference in collection development policy is for journals and other types of serials to be accessible in electronic form. This preference is driven by factors such as space constraints that put a limit on how many print resources may be made available to users, and the fact that electronic access allows for access by multiple users and also remote users. In practice, this preference is mitigated by the budgetary constraints under which the VUW Central Library operates, and so, Innes says, "... although our policy is for electronic, sometimes for financial reason we purchase print." 127

However, she does say that the Central Library tries to go with the preference of its users, both students and staff, and adds that "...there are a lot of students and staff preferring electronic [resources]"128 In contrast, Manhire would prefer journals to be provided in print so that his students do not lose out on the reading experience.

At the VUW Central Library, the policy that guides collection development is in a state of flux. The previous, more general, policy has been put aside because "...like many policies [it] didn't say a great deal in general... it was trying to take into account all circumstances and it was not terribly prescriptive." ${ }^{129}$ New subject-based policies and collection profiles are being developed in the hope of better understanding the information needs of students and staff and consequently being in a better position to meet them.

Innes also said that "at the moment we are just going with the very general idea that we are supporting the teaching and research needs of staff and students therefore what they want in the collection is what guides us." 130 In addition to this, the collection development team are doing some anticipatory purchasing of fiction - not for specific courses, but to build a broader and more comprehensive fiction collection for the future. This includes award-winning fiction, children and young adults' fiction, and

\footnotetext{
${ }^{126}$ Mary Innes, Interview by author, Tape recording. Wellington, New Zealand, 12 May 2006.

${ }^{127}$ Innes, Interview by author, 12 May 2006.

${ }^{128}$ Innes, Interview by author, 12 May 2006.

${ }^{129}$ Innes, Interview by author, 12 May 2006.

${ }^{130}$ Innes, Interview by author, 12 May 2006.
} 
playscripts. In the past, purchasing of fiction was principally of New Zealand authors (with a few exceptions).

Widening the scope of the contemporary fiction collection will, to some extent, address the issue a number of the questionnaire respondents noted in their completed questionnaires, in that the fiction available from the VUW Central Library was, they felt, out-of-date and severely limited in its scope of published authors (see section 3.1.4). Bill Manhire also noted that the current collection influenced him not to recommend the VUW Central Library.

Furthermore, the VUW Central Library does provide resources specifically, but not exclusively, for the Creative Writing students. These include publications from book and author lists provided by the Institute's teaching staff to the collection development team as well as the Institute's previous students' thesis manuscripts. The manuscripts are kept in a special collection within the Beaglehole Room, which houses all of the libraries' special collections. Access to these student manuscripts is restricted and requires permission from the author to view.

With regards to journals, there are none provided specifically for the MA (Creative Writing) programme and instead those journals provided are for use across all of the English programmes.

Innes described the relationships which the VUW Central Library has with the Institute in terms of her relationship with it. This relationship is, she says, "...really at the end of the email..."131 where lecturers contact her with purchase requests in various forms, for example purchase lists, circled entries in publishers' catalogues and so on. Understandably she sees the relationship as remote despite its two-way nature; she circulates catalogues and other material to teaching staff.

Although the library is equipped to notify teaching staff of new publications in their area through an Auto Alert system," $" 132$ the Institute has not been set up to receive this service and Innes felt that it would be difficult to do so as there is a great deal of contemporary fiction and other literature being published and no easy way to filter it. Departments such as Anthropology or Social Policy may easily filter what they need from the "glut" of publications by only looking at those that fit with the LCC numbers of their subject.

There is more contact with the Head of the English Department, under which the Institute falls, who is notified of current levels of budgeting for allowed spending on monographs, journals and other resources.

When asked what types of relationships the Central Library had with student writers, Innes said "I'm unfortunately, like I say, a bit isolated and I don't have any relationship with student writers..."134 unless they contacted her directly. Her understanding of them and their needs came through her relationship with the Liaison Librarian for English. She did say, however, that she "... would be very happy to see

\footnotetext{
${ }^{131}$ Innes, Interview by author, 12 May 2006.

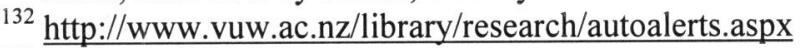

${ }_{133}$ Library of Congress Classification: http://www.loc.gov/catdir/cpso/lcco/lcco.html

${ }^{134}$ Innes, Interview by author, 12 May 2006.
} 
them..."135 with regards to collection development and what they would like to see in the library.

The final question in the interview schedule (Appendix E) asked whether the Victoria University Central Library hosted any promotional events to support VUW writers, either student writers or writers in residence.

Occasionally there are displays in glass display cases, either on level 2 of the Central Library (the entry level) or in the Beaglehole Room. At least two copies of those publications produced by the Victoria University Press are purchased by the Central Library for their shelves. The Central Library also tries to buy publications by staff. If collection development staff notice a publication by a former VUW student they will try to acquire that too.

In relation to actual promotional events, however, Innes was unaware of any being organised by the Central Library. She was aware that they did host events, like poetry readings, at the Stout Research Centre for New Zealand Studies, ${ }^{136}$ which is located on the same campus (Kelburn) on which the Central Library and the Institute are located.

From this interview it could be seen that there is little "real" communication between the VUW Central Library and the Institute.

\section{Conclusions}

From these findings, within the theoretical frameworks outlined in Section 1.1, the research questions developed for this study have been answered. Other significant findings are also highlighted, and from these conclusions a recommendation is made. Finally, the study's limitations are elucidated with a discussion of how these limitations may be addressed in further research.

\subsection{Result Summary}

The information needs of IIML students are principally those associated with gaps in their knowledge with regards to particular writing techniques or styles, and also inspiration. To meet these needs they frequently use other writers' work to provide them with examples of technique and style. The type of other writers' work used was, in part, dictated by the type of creative writing in which the student engaged. Often the material they find to meet these needs is sourced from libraries, and so libraries have an indirect impact on the creative writing process.

Creative writing students make use of libraries because they provide a wider range of material than students could develop in their own personal collections. The main library that they used during 2005 was the Institute's Class Library, followed by public libraries and, finally, the VUW Central Library. The students also used certain libraries in preference to others; namely the IIML Class Library and public libraries in

\footnotetext{
${ }^{135}$ Innes, Interview by author, 12 May 2006.

${ }^{136} \mathrm{http} / /$ www.vuw.ac.nz/stout-centre/index.aspx
} 
preference to the VUW Central Library. The main reason for this choice on the part of students was that, compared to the Central Library, the Class Library was in close proximity to the Institute; students generally perceived the collection to be of high quality; the collection was more accessible; and reading material was readily available. The main reason for choosing not to use the VUW Central Library was that it frequently did not have the resources that respondents required. Other factors that contributed to the low preference for using the VUW Library were its unattractive physical spaces and high noise levels.

Another factor that may have affected the usage of the examined libraries is library anxiety. Students experienced strong positive feelings, such as "motivation" and "confidence," when using the IIML library, but, in contrast, students frequently experienced negative feelings such as "anxiety" and being "unsure" when using the Central Library. One student recounted in detail the anxiety they experienced when using academic libraries in general, and there were comments throughout the questionnaire about how students found the VUW Central Library intimidating.

\subsubsection{Other Findings}

In addition to answering the specific research questions, a number of other findings could be made based on the data collection.

- The creative writing space of students is frequently in their own homes, where they are most likely to be comfortable and relaxed, and which they could also customise to meet their specific physical needs. Libraries were not found to be providers of creative writing space, nor were they promoted as such.

- Satisfaction levels with the Class Library and the VUW Central Library indicated that, for collection quality and physical space, students were more satisfied with the Class Library, but were not more satisfied with regards to equipment. This factor may have a correlation with library usage, but this cannot be stated explicitly based on the findings of this study.

- Despite the current popularity of access to electronic resources via the World Wide Web, the Institute's students, and its Director, preferred to read resources in print. This is due to differences in reading experience between physical and virtual media.

- Another finding of this study was that there is little done in the VUW Library, or indeed other libraries of which the focus group participants were aware, in terms of promoting creative writing students' work to the public.

- Many interrelationships between creative writers, libraries and society were expressed. The principal relationships include:

- Creative writing

- Touches on universal themes and highlights these for individuals;

- Can entertain and inspire;

- Is perceived to be an essential component of culture and can provoke change;

- Acts as a historical document for human social and mental evolution;

- Produces the material with which libraries stock their shelves;

- Provides libraries with community-based support. 
- Libraries

- Supply resources to both creative writers and society in an accessible and "free" manner;

- Contribute to the "mental wellbeing" of society;

- Provide community spaces.

○ Society

- Provides creative writers with feedback and engages them in societal dialogue;

- Provides a context in which libraries and creative writers exist.

\subsection{Recommendations}

There are a small number of recommendations that can be made based on the findings of this study. Despite the recent improvement and ongoing plans to improve the range of contemporary literature in the VUW Central Library collection, the other, noncollection-relating, factors that drive students to use other libraries in preference to the Central Library will, in all likelihood, still exist (see Section 4.1). The Institute's Class Library as it stands also has limitations but these do not seem to have a significant impact on its usage by Creative writing students and so it is recommended that the Class Library be retained as a separate collection.

To ensure that the Class Library continues to be used at the level at which it was used last year (2005), it is recommended that, funding allowing, the Institute attempt to meet the suggestions made by creative writing students in the questionnaire (Questions 13 and 29).

These may be summarised as follows:

- Including more diversity in the collection with regards to format such as adding more scripts, plays, craft and theory texts and so on;

- Widening the scope of the existing material to include more works by nonNew Zealanders;

- Adding a DVD collection of suitable films for screenwriting students, as well as magazine collections in DVD format.

This recommendation is contingent on the premise that the Class Library remains a viable resource for students in the future. This projection will most likely remain true unless the VUW Central Library is able to take a more direct interest in the information needs of Creative Writing students and addresses more aggressively the issues outlined by the Institute's students and staff.

\subsection{Study Limitations and Implications for Further Study}

As noted in the Section 2, the small sample population of Creative Writing students places a severe limitation on the validity of the findings of this project. There were seventeen responses to the questionnaire, which is just over half of the entire sample population. Also, there were only three participants in the focus-group interviews.

Only one staff member was willing to be interviewed, and so there are likely to be other points of view not explored in this project which might have had a significant impact on the findings above. 
These limitations, however, point to further research in this area which needs to be done to further clarify, or correct, the findings generated by this research project. Further study could include longitudinal studies to widen the sample population or conducting studies at other institutions that offer post-graduate creative writing courses that also supply their students with a specialist class library.

The relationships between the identified variables need to be further explored: for example, how satisfaction levels may affect usage is unknown.

The feelings experienced by Creative Writing students when using the IIML Library could perhaps be attributed to its proximity to the programme's teaching space and the creative mindset that students engage in when they are learning, but further study would need to be undertaken to support this conclusion. The emphasis placed on particular libraries by IIML teaching staff may also be a factor that governs usage.

To determine how much of a factor library anxiety is on library usage, more extensive trials should be conducted with similar populations using the developed library anxiety testing instruments.

Much research needs to be done to further contextualise the place and importance of creative writers in society. This indicates that further elucidation of the relationships between libraries and creative writers, especially those pertaining to the creative writing process, is needed.

The knowledge gap in the literature with regards to the topic of this study is large, and will require more research before it is able to be bridged. 


\section{Bibliography}

Alexander, Keith. "Identifying and Managing Facilities Needs." Facilities 11, no. 3 (1993): 18-21.

Antell, K. "Why Do College Students Use Public Libraries? A Phenomenological Study." Reference \& User Services Quarterly 43, no. 3 (2004): 227-36.

Bainbridge, David, Sally Jo Cunningham, and J. Stephen Downie. "How People Describe Their Music Information Needs: A Grounded Theory Analysis of Music Queries." Paper presented at ISMIR, John Hopkins University, Baltimore, Maryland, 26-30 October 2003.

Barrie, Cameron. "A Mouthpiece of Writers: The Contribution of Australian Libraries." The Australian Library Journal 48, no. 3 (1999): 263-9.

Byström, Katriina and Kalervo Järvelin. "Task Complexity Affects Information Seeking and Use." http://www.info.uta.fi/tutkimus/fire/archive/KB20.pdf [Accessed 11 May 2006]

Chepesiuk, Ron. "Writers at Work: How Libraries Shape the Muse." American Libraries 25, no. 11 (1994): 984-7.

Cullen, Rowena. "Perspectives on User Satisfaction Surveys." Library Trends 49, no. 4 (2001): 662-86.

Cunningham, Sally Jo, David Bainbridge, and Masood Masoodian. "How People Describe Their Image Information Needs: A Grounded Theory Analysis of Visual Art Queries." Paper presented at the Proceedings of the ACM/IEEE Joint Conference on Digital Libraries, Tucson, Arizona, 7-11 June 2004.

Davis, Jinnie Y. "Writers and Libraries: A Symbiotic Partnership - Author Programs at North Carolina State University." North Carolina Libraries 57, no. 2 (1999): 57-61.

Eskola, Eeva-Liisa. 'University Students' Information Seeking Behaviour in a Changing Learning Environment - How are Students' Information Needs, Seeking and Use Affected by New Teaching Methods?" Information Research 4, no. 2 (1998). http://informationr.net/ir/4-2/isic/eeskola.html [Accessed 11 May 2006]

Eubank, Susan. "Silas House: What the Library Did for Me." Kentucky Libraries 65, no. 3 (2001): 3-5.

Foster, David. "Reading(s) in the Writing Classroom." College Composition and Communication 48, no. 4 (1997): 518-39.

Freiman, Marcelle. "Crossing the Boundaries of the Discipline: A Post-Colonial Approach to Teaching Creative Writing in the University." Text 5 no. 2 
(2001). http://www.gu.edu.au/text/school/art/text/oct01/freiman.htm [Accessed 8 August 2005]

Giardinelli, Mempo. "The Library in the Life of a Writer." IFLA Journal 30, no. 4 (2004): 288-92.

Henczel, Sue. "To be Truly Accountable to Your Clients, Identify Their Needs." Information Outlook 9, no. 2 (2005): 32-3.

Innes, Mary. Interview by author. Tape recording. Wellington, New Zealand, 12 May 2006.

Interview with focus groups by author. Tape recording. Wellington, New Zealand, May 2006.

Jiao, Qun G., and Anthony J. Onwuegbuzie. "Prevalence and Reasons for University Library Usage." Library Review 46, no. 6 (1997): 411-20

Kuhlthau, Carol Collier. "The Information Search Process." In Seeking Meaning: A Process Approach to Library and Information Services, 33-53. Norwood, N.J.: Ablex, 1993.

Light, Gregory. "From the Personal to the Public: Conceptions of Creative Writing in Higher Education." Higher Education 43 no. 2 (2002): 357-76.

Manhire, Bill. Interview by author. Tape recording. Wellington, New Zealand, 5 May 2006

Matthews, Joseph R. "Determining and Communicating the Value of the Special Library." Information Outlook 7, no. 3 (2003): 26-31.

Mellon, Constance A. "Library Anxiety: A Grounded Theory and Its Development." College \& Research Libraries 47, no. 5 (1986): 160-5.

Miller, E. Ethelbert. "A Writer's View: "Journey to a Sacred Place"." American Libraries 31, no. 6 (2000): 67-8.

Miller, Lynette. "User Satisfaction Surveys." Australasian Public Libraries and Information Services 17, no. 3 (2004): 125-33.

Onwuegbuzie, Anthony J., and Qun G. Jiao. "Understanding Library-Anxious Graduate Students." Library Review 47, no. 4 (1998): 217-224.

Onwuegbuzie, Anthony J., Qun G. Jiao, and Sharon L. Bostick. "Library Anxiety: Theory, Research, and Applications." In Research Methods in Library and Information Studies \#1, edited by R. R. Powell and L. Westbrook. Lanham, Maryland: The Scarecrow Press Inc., 2004.

Reed, Bonnie, and Donald R. Tanner. "Information Needs and Library Services for the Fine Arts Faculty." Journal of Academic Librarianship 27, no. 3 (2001): 
229-33.

Reed, Philippa. "Writing Activities in Libraries." Assistant Librarian 88, no. 2 (1995): 28-30.

Shi, Xi. "A Theory-guided Approach to Library Services Assessment." College \& Research Libraries 66, no. 3 (2005): 266-77.

Simmonds, Patience L., and Syed Saad Andaleeb. "Usage of Academic Libraries: The Role of Service Quality, Resources, and User Characteristics.” Library Trends 49, no. 4 (2001): 626-34.

Van Kampen, Doris J. "Development and Validation of the Multidimensional Library Anxiety Scale." College \& Research Libraries 65, no. 1 (2004): 28-34.

Wilson, T. D."Models in Information Behaviour Research." The Journal of Documentation 55. no.3 (1999):249-70. 


\section{Appendix A - Project Gantt Chart}

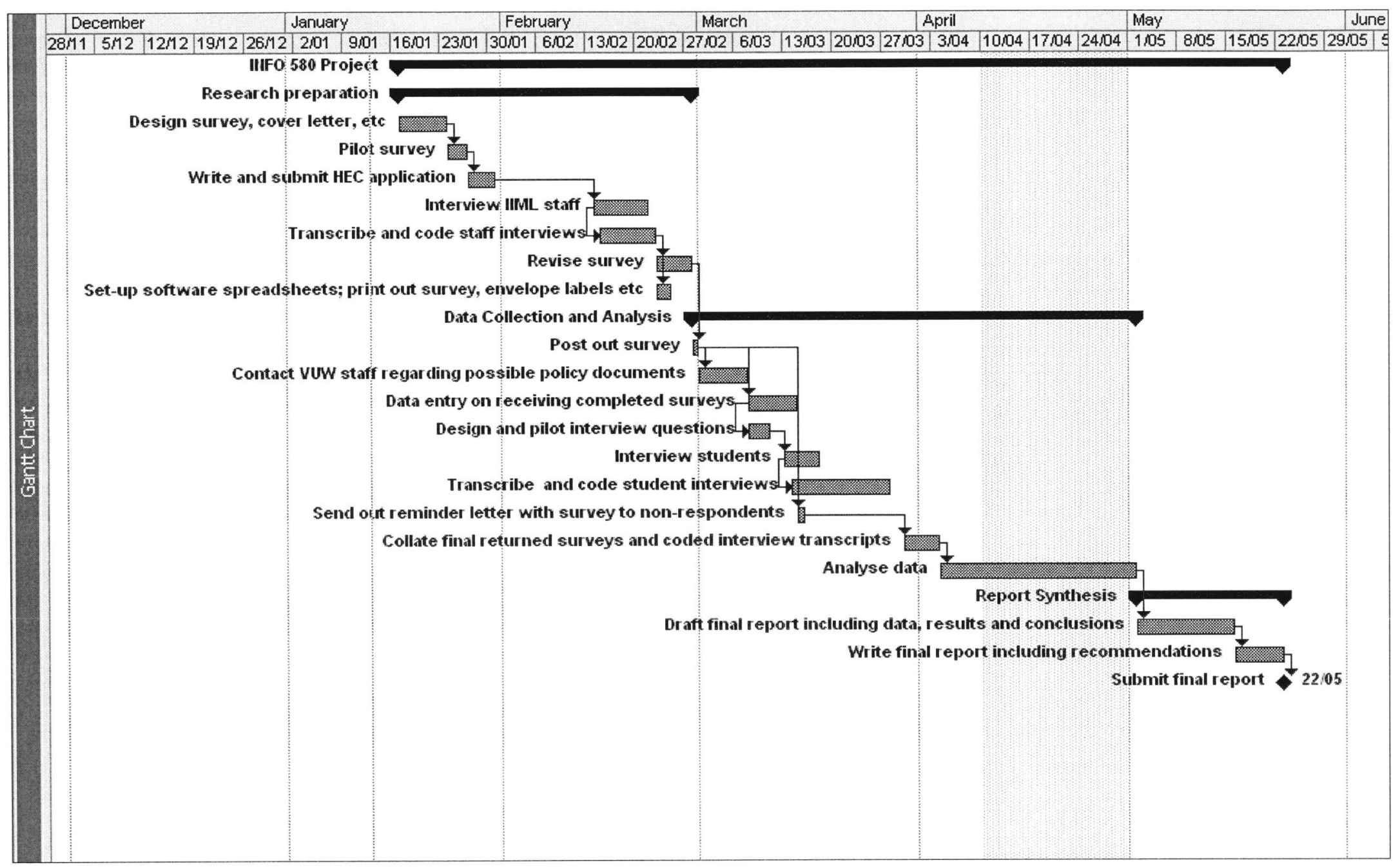




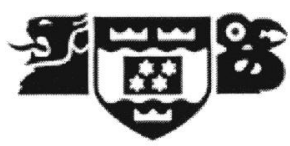

\section{SCHOOL OF INFORMATION MANAGEMENT}

\section{Appendix B - Student Survey}

\section{Library requirements of Masters of Creative Writing Students: Is the Class Library of The International Institute Modern Letters meeting their information needs?}

This questionnaire is intended to discover how, what for and when Master of Creative Writing students use library resources during the course of their studies - this is to aid the International Institute of Modern Letters in determining whether it should retain its library collection separately from that of the Victoria University of Wellington Libraries network.

The survey is intended to take around 15-20 minutes to complete. Please answer the questions below in relation to your study/writing environment as it was in 2005.

Definitions:

$>$ Class library or collection: A collection of 'teaching' resources made available to students belonging to a specific discipline by their faculty.

$>$ IIML or Institute: The International Institute of Modern Letters

$>$ Information needs: An expressed or unconscious need for information experienced by an individual or groups of people.

$>$ Library requirements: Information requirements that may be met through the resources of a library.

> VUW: Victoria University of Wellington

Reading, Libraries and the Creative Writing Process:

1. What did you take from reading other writers' works?

e.g. pleasure, escapism, an example of style or technique etc

2. When you wrote, where did you write?

e.g. café, VUW library, in my bedroom etc.

3. What type of writing did you mostly produce?

e.g. poetry, mystery novels etc 


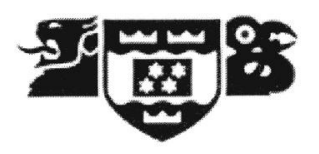

\section{SCHOOL OF INFORMATION MANAGEMENT}

4. What did you need in the space where you wrote?

Tick as many as is appropriate.

$\square$ People - for background noise, support etc

$\square$ Privacy

$\square$ Books and other reading materials

$\square$ Lots of space

$\square$ Lots of light

$\square$ A desk or table

$\square$ A computer

Other:

5. How often did you use other writers' works when you wrote?

Please tick one.

$\square$ Not at all

$\square$ Not very often

$\square$ Often

$\square$ Quite often

6. How did you make use of other writers' works when you wrote?

7. What type of other writers' work did you use when you wrote?

Tick as many as is appropriate.

Non-fiction:

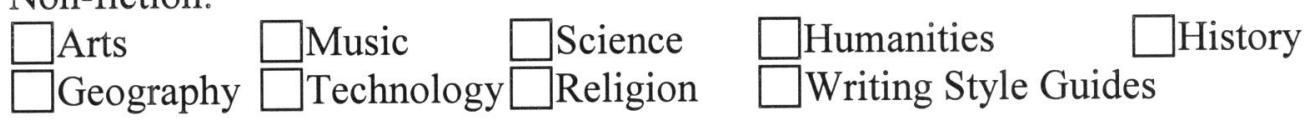

Fiction:

$\square$ Poetry $\square$ Short fiction $\square$ Plays $\quad \square$ Novels

8. Are there any others not listed above?

\section{Library Usage:}

9. Where did you find the material that you read?

Tick as many as is appropriate.

$\square$ I owned it
$\square$ I borrowed from friends, family, classmates etc
$\square$ I borrowed it from the IIML Class library
$\square$ I borrowed it from the VUW libraries
$\square$ I borrowed it from a public library




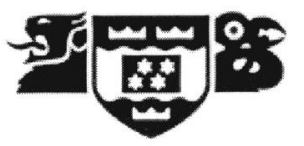

\section{SCHOOL OF INFORMATION MANAGEMENT}

Other:

10. What general features of those libraries you used encouraged you to use them? e.g. Friendly staff, lots of resources etc.

11. If you used libraries other than, or in addition to, that of VUW, what did these other libraries offer that encouraged you to use them?

e.g. More comfortable using the public library etc.

12. How often did you use the IIML collection?

Please tick one.

$\square 2$ or more times/day

$\square$ once/day

$\square$ twice or more/week

$\square$ once/week

Donce/fortnight

$\square$ once/month

$\square$ Never

13. What would you have liked to have seen in the collection? What other features would you have liked added? e.g. More non-fiction, an electronic catalogue etc

14. How often did you use the VUW libraries?

Please tick one.

$\square 2$ or more times/day

Donce/day

$\square$ twice or more/week

$\square$ once/week

$\square$ once/fortnight

once/month

$\square$ Never

15. How often did you use the public libraries?

Please tick one.

$\square 2$ or more times/day
$\square$ once/day
$\square$ twice or more/week
$\square$ once/week
$\square$ once/fortnight
$\square$ once/month
$\square$ Never




\section{VICTORIA UNIVERSITY OF WELLINGTON}

Te Whare Wānanga o te Ūpoko o te Ika a Mãui

\section{SCHOOL OF INFORMATION MANAGEMENT}

\section{User Satisfaction:}

How would you have rated your satisfaction level with:

16. The collection of IIML

Please tick one.

$\square$ High $\square$ Fairly high $\square$ Neutral $\square$ Fairly low $\square$ Low $\square$ Don’t know

17. The physical space in which the collection is housed Please tick one.
$\square$ High
Fairly high
$\square$ Neutral
$\square$ Fairly low
$\square$ Low
$\square$ Don't know

18. The equipment (computer, card catalogue etc) in the library Please tick one.
$\square$ High
$\square$ Fairly high
$\square$ Neutral
$\square$ Fairly low
$\square$ Low
Don't know

How would you have rated your satisfaction level with:

19. The library staff of VUW central library

Please tick one.

$\square$ High $\square$ Fairly high $\square$ Neutral $\square$ Fairly low $\square$ Low $\square$ Don't know

20. The collection of VUW central library

Please tick one.

$\square$ High $\square$ Fairly high $\square$ Neutral $\square$ Fairly low $\square$ Low $\square$ Don’t know

21. The VUW central library building

Please tick one.

$\square$ High $\square$ Fairly high $\square$ Neutral $\square$ Fairly low $\square$ Low $\square$ Don't know

22. The equipment in the VUW central library

Please tick one.

$\square$ High $\square$ Fairly high $\square$ Neutral $\square$ Fairly low $\square$ Low $\square$ Don’t know

\section{Libraries and their effect on how you feel:}

23. When using the IIML class library, did you feel:

Tick as many as is appropriate.

$\square$ Supported
$\square$ Motivated
$\square$ Confused
$\square$ Uncomfortable
$\square$ Anxious
$\square$ Unsure
$\square$ Comfortable
$\square$ Confident
$\square$ Inspired




\section{SCHOOL OF INFORMATION MANAGEMENT}

24. When using the VUW libraries, did you feel:

Tick as many as is appropriate.

\begin{tabular}{l}
$\square$ Supported \\
\hline$\square$ Motivated \\
$\square$ Confused \\
$\square$ Uncomfortable \\
$\square$ Anxious \\
$\square$ Unsure \\
$\square$ Comfortable \\
$\square$ Confident \\
$\square$ Inspired
\end{tabular}

25. When using the public libraries, did you feel:

Tick as many as is appropriate.

\begin{tabular}{l}
$\square$ Supported \\
\hline$\square$ Motivated \\
\hline$\square$ Confused \\
\hline$\square$ Uncomfortable \\
\hline$\square$ Anxious \\
\hline$\square$ Unsure \\
\hline Comfortable \\
\hline$\square$ Confident \\
\hline$\square$ Inspired
\end{tabular}

26. Do you think the IIML class library should be kept separate (within the Glenn Schaeffer Building) or integrated into the VUW Central library? Please give a reason for your opinion.

Finally, the two writers quoted below have noted the importance of reading and libraries in their writing lives.

Silas House said:

"The only way to be a good writer is to read great books..."

27. Do you agree with him on the importance of reading in being a good writer? Please give a reason for your answer. 


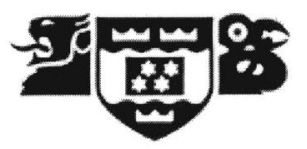

\section{SCHOOL OF INFORMATION MANAGEMENT}

The second quote is from Mempo Giardinelli who said:

"I learned at...[a range of libraries]...that the best thing to do was read at random hut, as somerne hroathes, incessantly and vitally."

28. Do you agree with him on the importance of libraries in the creative writing process? How do you feel about his statement?

29. Do you have any other comments you would like to make, that are relevant to this study?

Thank you very much for completing this survey.

Please see overleaf for information on returning the completed questionnaire. 


\section{Appendix C - Student Interview Schedule}

\section{Interview Schedule (Students)}

Importance of writing to society

What importance do you think creative writing has to society? How much of your work do you feel is part of the 'dialogue' of society/reflects themes that are topical?

Why become writers?

Importance of libraries to creative writing

How does reading induce/inspire the writing urge in you? Did your early experience with libraries in anyway inspire your choice to become a writer?

Establish relationships: between writers, libraries and society

How important is publishing to the writing self? How important is the physical published object? Are you published?

What relationships do you have with libraries? Are any libraries working with you to promote your work? Has VUW, or any other library, made any attempts to promote your writing?

What do you think makes up the relationships or contacts between writers, libraries and society?

\section{Quotes}

What do you think about the following quotes? Do you agree/disagree? Are there themes that aren't touched upon that you feel are important?

"...every writer that speaks about reading begins by evoking the library that moulded him." - Mempo Giardinelli

"I am...certain that my role as a writer derived from my education as a reader...[a] book education that, above all, stimulated freedom and limited curiosity." - Mempo Giardinelli

"Libraries gave creative writers the opportunity to read the work of a wide variety of authors. This provided them with inspiration and ideas for their work." - Cameron Barrie

"Read, read, read. Read everything - trash, classics, good and bad, and see how they do it. Just like a carpenter who works as an apprentice and 
studies the master. Read! You'll absorb it. Then write. If it's good, you'll find out. If it's not, throw it out of the window." - William Faulkner

"The unread story is not a story; it is little black marks on wood pulp. The reader, reading it, makes it live: a live thing, a story." - Ursula K Le Guin

"Translation is entirely mysterious. Increasingly I have felt that the art of writing is itself translating, or more like translating than it is like anything else. What is the other text, the original? I have no answer. I suppose it is the source, the deep sea where ideas swim, and one catches them in nets of words and swings them shining into the boat ... where in this metaphor they die and get canned and eaten in sandwiches." - Ursula K Le Guin

"From every book invisible threads reach out to other books; and as the mind comes to use and control those threads the whole panorama of the world's life, past and present, becomes constantly more varied and interesting, while at the same time the mind's own powers of reflection and judgment are exercised and strengthened."

- Helen E. Haines

"A bibliophile of little means is likely to suffer often. Books don't slip from his hands but fly past him through the air, high as birds, high as prices." - Pablo Neruda

"The final lesson a writer learns is that everything can nourish the writer. The dictionary, a new word, a voyage, an encounter, a talk on the street, a book, a phrase learned." - Anais Nin 


\section{Appendix D - IIML Staff Interview Schedule}

\section{Interview Schedule (IIML Staff)}

As a writer

- What do you take from reading?

- How did you become a writer?

- How do you use what you take?

- Where do you find your reading material?

- Which libraries do you use?

- How do you think libraries contribute to your writing process?

As a teacher

- How much emphasis, as a teacher, do you put on libraries as:

- Provider of resources?

- Provider of 'expert' assistance in locating material?

- Provider of creative/writing space?

- Which libraries do you recommend to your students?

- What other resources do you recommend in preference to libraries? 


\section{Appendix E - VUW Librarian Interview Schedule}

\section{Interview Schedule (VUW Librarian)}

- How do you identify the information needs of Masters level Creative Writing students?

- How is your policy structured to meet these needs?

- What resources do you provide specifically for Creative Writing students?

- In terms of the existing collection - how well do you think that it meets the information needs of Creative Writing students?

- What type of relationships does the library have with:

- The International Institute of Modern Letters?

$\circ$ Student writers?

- Does the library run promotional events to support VUW writers (either students or writers in residence)? 